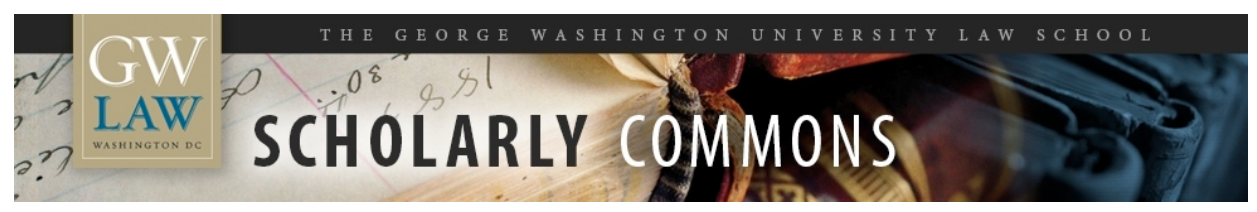

\title{
Why Do Women Lawyers Earn Less than Men? Parenthood and Gender in a Survey of Law School Graduates
}

Neil H. Buchanan

George Washington University Law School, neilhbuchanan@gmail.com

Follow this and additional works at: https://scholarship.law.gwu.edu/faculty_publications

Part of the Law Commons

\section{Recommended Citation}

Buchanan, Neil H., "Why Do Women Lawyers Earn Less than Men? Parenthood and Gender in a Survey of Law School Graduates" (2008). GW Law Faculty Publications \& Other Works. 315.

https://scholarship.law.gwu.edu/faculty_publications/315

This Article is brought to you for free and open access by the Faculty Scholarship at Scholarly Commons. It has been accepted for inclusion in GW Law Faculty Publications \& Other Works by an authorized administrator of Scholarly Commons. For more information, please contact spagel@law.gwu.edu. 
Draft of October 2, 2008

Do not quote or cite without written permission from the author.

Why Do Women Lawyers Earn Less than Men?

Parenthood and Gender in a Survey of Law School Graduates

Neil H. Buchanan, J.D., Ph.D.

Associate Professor of Law

The George Washington University Law School

2000 H Street, N.W.

Washington D.C. 20052

(202) 994-3875

nbuchanan@law.gwu.edu 


\begin{abstract}
$\underline{\text { Abstract }}$
Using a dataset of survey responses from University of Michigan Law School graduates from the classes of 1970 through 1996, I find that fathers tend to receive higher salaries than non-fathers (a “daddy bonus”). In addition, mothers earn less than nonmothers (a "mommy penalty"). There is also some statistical support for the inference that there is a penalty associated purely with gender (women earning less than men, independent of parenthood), another result that is unique to the literature.

Analyzing full- or part-time status as well as work hours also suggests a key difference between women and men. Those who take part-time status are almost entirely women who take on child-rearing duties, and they reduce their work hours by an average of approximately thirty percent. These statistical results are, however, significantly less reliable because of the very small numbers of respondents (male or female) who work less than full time.
\end{abstract}




\section{Contents}

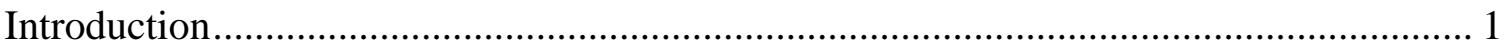

I. Two Surveys of University of Michigan Law School Graduates .................... 2

A. A Survey of University of Michigan Law School Graduates: The Professional Development Survey (PDS) .................................................................. 5

Key Results of the Analysis of the PDS Survey …..................... 7

B. Adding Information on Gender and Family Life: The Supplementary

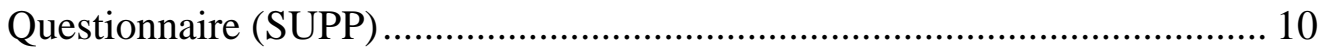

C. Statistical Issues in Comparing the Two Surveys..................................... 12

Non-Response Bias Among Respondents to the Two Surveys . 12

Comparing Respondents to the Two Surveys .......................... 15

Congruence with Previous Results ......................................... 18

II. How Do Gender and Family Status Affect Earnings? .................................. 23

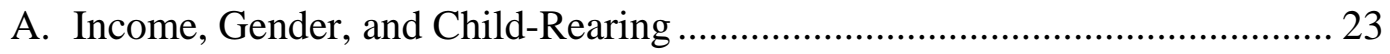

B. Work Status: Full-Time, Part-Time, and Not Employed ............................... 32

A Note Regarding Binary Dependent Variables...................... 33

Full-Timers, Part-Timers, and Not Employed in the

Supplementary Questionnaire...................................... 36

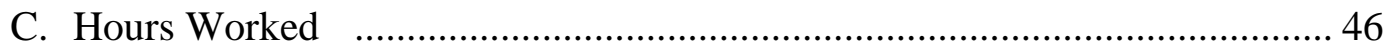

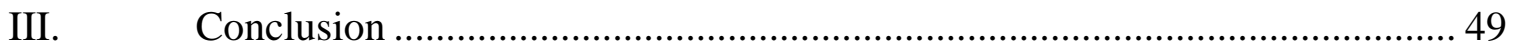




\section{Introduction}

While women continue to make important and impressive inroads in the learned professions in the United States, their salaries continue to lag behind those of men. It is important to determine whether this is due to outright hostility, hidden bias, or seemingly neutral factors (factors which, however, might themselves be related to gender in unique ways). This paper summarizes an analysis of survey data of almost thirty graduating classes of students who attended the University of Michigan Law School and earned a juris doctorate degree (J.D.), data which had until recently been unavailable for independent scholarly analysis.

The analysis presented here focuses on gender- and family-related factors that are likely to affect the career paths and outcomes of men and women in potentially different ways. Controlling for other factors, I confirm a finding noted in studies of similar populations that fathers tend to receive higher salaries than non-fathers (a "daddy bonus”). Contrary to previous studies, however, my results indicate that mothers earn less than non-mothers (a "mommy penalty”). There is also some statistical support for the inference that there is a penalty associated purely with gender (women earning less than men, independent of parenthood), another result that is unique to the literature.

Analyzing full- or part-time status as well as work hours also suggests a key difference between women and men who responded to the survey. Those who take parttime status are almost entirely women who take on child-rearing duties, and they reduce their work hours by an average of approximately thirty percent. These statistical results are, however, significantly less reliable because of the very small numbers of respondents 
(male or female) who work less than full time.

These results thus confirm and extend our understanding of the gender dynamics of lawyers' earnings and work lives. Further work is under way to explore these matters in still greater depth.

\section{Two Surveys of University of Michigan Law School Graduates}

The University of Michigan Law School enrolls a highly talented entering class of students each year, students who go on to careers in every corner of legal practice as well as to a wide variety of careers outside of the practice of law. In 1997 and 1998, over one thousand alumni of the law school who had graduated between 1970 and 1996 submitted answers to the Professional Development Survey (PDS), which contained dozens of detailed questions designed to elicit important information about the careers of Michigan Law graduates. Of those who responded to the PDS, over seven hundred alumni also responded to a shorter follow-up Supplemental Questionnaire (SUPP) in 1999.

The dataset that contains the responses to the PDS and the SUPP is a rich source of important information about the graduates of one of this country's most selective law schools. The designers of the survey, University of Michigan law professors Richard Lempert and David Chambers and senior research associate Terry Adams, conducted an extensive statistical analysis of the data from the original PDS. As part of an effort to understand the importance of race in the law school and career experiences of Michigan’s J.D. recipients, these scholars analyzed the PDS survey responses to determine which variables predicted success, both in law school and thereafter, as measured by a variety of 
criteria. The fruits of that investigation are described in “Michigan’s Minority Graduates in Practice: The River Runs Through Law School”1 (hereinafter referred to as LCA). As impressive as their analysis is, though, it is only the tip of the iceberg in terms of what we might learn from this rich set of survey responses.

As discussed in some detail below, the statistical results in LCA shed important light on the affirmative action debate, showing that the so-called "hard" criteria for law school admissions (undergraduate grade-point averages and LSAT scores) are generally not predictive of career success or satisfaction. While these findings provide important insight into the continuing controversy over affirmative action programs at Michigan and elsewhere, ${ }^{2}$ they were not originally intended for that purpose. ${ }^{3}$ Even in the absence of the lawsuit unsuccessfully challenging the law school's affirmative action program, the continuing importance of race in American life called out for a careful analysis of how race and legal education interact.

Although women still constitute significantly less than fifty percent of entering law classes at Michigan, they have become an integral part of the law school's student

1 Richard O. Lempert et al., Michigan’s Minority Graduates in Practice: The River Runs Through Law School, 25 L. \& SoC. INQUIRY 395 (2000), hereinafter LCA.

$2 \quad$ Grutter v. Bollinger, 539 U.S. 306 (2003).

3 Richard O. Lempert et al., Michigan's Minority Graduates in Practice: Answers to Methodological Queries, 25 L. \& Soc. INQUIRY 585, 586 (2000) (“... [A]lthough we knew that Michigan was among the schools that might be targeted for a lawsuit, planning for our study began more than a year before the lawsuit was filed”). 
body in the last few decades. ${ }^{4}$ There are important differences between racial groups in the representation of women in the law school, with women being a larger part of minority student populations than they are among white students. ${ }^{5}$ While LCA statistically control for this difference and note instances where it might matter, ${ }^{6}$ the emphasis of that analysis is squarely (and appropriately) on race. ${ }^{7}$

Among the commissioned responses to LCA simultaneously published in Law \& Social Inquiry, though, one response ${ }^{8}$ specifically and emphatically called for a genderoriented analysis: "We recognize that it is impossible to do everything in one article. Yet

$4 \quad$ University of Michigan Law School, Law School Facts (last visited Oct. 2, 2008) <http://www.law.umich.edu/newsandinfo/pages/facts.aspx\#students> (showing that women make up 43\% of students in the class of 2008 and $45 \%$ in both the classes of 2009 and 2010, and also showing that $24 \%$ of living graduates are women).

5 LCA at 400 (noting that the higher representation of women among Michigan law students is reflected in the responses to the PDS: $24.2 \%$ of white respondents to the PDS are women, whereas $37.5 \%$ of minority respondents are women).

6 See “A Note on Gender,” LCA at 400-01.

7 Indeed, the regression results that LCA report omit a gender/ethnicity interactive term, as well as a marital status term, because the authors found that those variables uniformly provided little explanatory power in the regressions on income, career satisfaction, and community service. LCA at 476.

8 Robert L. Nelson \& Monique R. Payne, Minority Graduates from Michigan Law School: Differently Successful, 25 L. \& SOC. INQUIRY 521 (2000). 
we want to underscore the importance of looking at the relationship between race and gender in legal careers."9

The analysis presented here is an initial attempt to address that relationship, ${ }^{10}$ focusing first on the comparability of the respondents to the PDS and the SUPP and then moving on to discuss statistical results that help to understand the differences between the legal careers of Michigan's female and male law graduates. Those results indicate that women uniquely bear the burdens of raising children — earning lower salaries, working part-time (or not at all) in paid jobs, and reducing their work hours even when they remain on the job. Even among such a talented and highly trained group of professionals, therefore, parenthood continues to carry quite different implications for women and men.

\section{A. A Survey of University of Michigan Law School Graduates: The Professional Development Survey (PDS)}

The original survey, called the Professional Development Survey (PDS), was sent to every minority graduate of the law school as well as a weighted sample of white graduates from Michigan’s graduating classes through $1996 .^{11}$

$9 \quad$ Id. at 524.

10 Unfortunately, Nelson and Payne's call for an analysis of the interactions of race and gender with class (id. at 521, "Of particular importance is the question of how, race, class, and gender interact to shape lawyers' careers...”) is beyond the scope of this analysis.

11 A methodological appendix available from Lempert et al. explains the methods used in designing the sample as well as related issues. 
The PDS, a ten-page long paper survey sent by mail to the selected recipients, included questions in six broad categories: Background Information (gender, date of birth, race/ethnicity, marital status), Law School Experience (questions regarding the law school's faculty, other students, student debt, etc.), Work Since Law School (information regarding first jobs after law school, current jobs, career satisfaction, community and professional service activities, income, etc.), special sections for Persons Not Practicing Law (regarding the role of their legal education in their current employment) and for Practicing Lawyers (regarding the types of clients served, pro bono work, mentoring, etc.), and a final section of open-ended questions regarding respondents' proudest accomplishments and most important goals. The responses to these questions generated 116 raw numeric variables, including continuous variables (such as income) as well as categorical variables (such as race and marital status).

In all, 2196 graduates received the PDS, and 1259 ultimately responded. Fortyone survey respondents graduated from the law school before 1970. (In addition, eleven respondents did not provide a graduation year, making their data unusable.) Because of the survey design, which emphasized gathering data from all minority graduates of the law school, all of those pre-1970 respondents were African-American. Of those 41 cases, only six were women, from graduating classes between 1944 and 1969. ${ }^{12}$ The 35 black male respondents graduated between 1935 and 1969. While each of these survey responses undoubtedly includes some valuable and fascinating information (indeed, how

\footnotetext{
12 Specifically, one female respondent graduated in 1944, two in 1950, one in 1954, one in 1962, and one in 1969.
} 
could one not be interested in what it was like to be a black woman at Michigan's premier law school in 1944?), these responses are too unique to be useful in a statistical analysis. They would be quite interesting as personal histories, but for LCA's purposes (as well as for the analysis presented here) they were set aside. Thus, LCA looked at 1207 responses to the PDS, representing an overall response rate of 56.3\% (1207 out of 2144 post-1970 graduates). ${ }^{13}$

\section{Key Results of the Analysis of the PDS Survey}

In their analysis of race and law school careers, Lempert and his co-authors provide a wealth of statistical tables and regression results, covering a broad range of questions. It would be both impractical and inappropriate to attempt to reproduce all of those results here, where the goal is to extend their analysis to take into account the new information available from a supplementary survey and to apply that information to the study of gender issues. Nevertheless, for the reasons discussed below, it is crucial to test the whether the respondents to the supplementary survey differed in important ways from those who responded to the PDS. Therefore, I provide below a summary of the key results of LCA's multiple regression analysis and compare the results of running those

\footnotetext{
13 The response rate for whites was notably higher than for non-whites, 51.4\% vs.
}

61.9\%, although the difference was smaller (and not statistically significant) for graduates in the classes of 1990-96. LCA analyzed the possibility of nonresponse bias and concluded, “[W]hile we can’t discard entirely the possibility of sample bias, we think it slight enough that it does not substantially distort the picture our data paint.” LCA at 405. 
same regressions on only those who responded to the supplementary survey.

The central regression results in LCA appear in three tables: Table 31 (“OLS Regression Results for Logged Income”), ${ }^{14}$ Table 33 (“OLS Regression Coefficients for Satisfaction Index"), ${ }^{15}$ and Table 35 ("OLS Regression Coefficients for Service Index"). ${ }^{16}$ While there are a variety of inferences that one can draw from those results, LCA emphasize the following findings (drawn from the regression analyses and from other statistical tests presented in their study): 1) Michigan’s minority graduates are more likely to begin their careers in government or public service, and they are less likely than whites to start their careers in private practice, although private practice is the most common work setting for all Michigan graduates, ${ }^{17}$ 2) Michigan's minority graduates are more likely to serve minority clients, to do more pro bono work, to sit on the boards of community organizations, and to do more mentoring of younger attorneys than white alumni do, ${ }^{18}$ 3) Michigan's minority alumni are highly successful and satisfied in their careers, even though they entered Michigan with lower LSAT scores and undergraduate grade-point averages (UGPA), which would have excluded many minority alumni from entering Michigan in the first place, had the admissions criteria been based exclusively on

$\begin{array}{ll}14 & \text { Id. at } 478 . \\ 15 & \text { Id. at } 486 . \\ 16 & \text { Id. at } 488 . \\ 17 & \text { Id. at } 401 . \\ 18 & \text { Id. }\end{array}$


these numerical criteria, ${ }^{19}$ and crucially 4) LSAT and UGPA “... correlate with law school grades, but they seem to have no relationship to success after law school, whether success is measured by earned income, career satisfaction, or service contributions.”20 These variables (LSAT and UGPA) “... seem to have virtually no value as predictors of post-law school accomplishments and success.”21

The latter point is particularly interesting, because the key statistical correlations do not "carry through.” That is, while it seems that LSAT and UGPA predict law school grades, ${ }^{22}$ and while it also appears that law school grades (LSGPA) predict income and, to some extent, service (but not career satisfaction), ${ }^{23}$ it does not seem to be true that an index combining LSAT and UGPA predicts any of the outcome variables. ${ }^{24}$ While there

\footnotetext{
$19 \quad$ Id. at $401-02$.

$20 \quad$ Id. at 401.

$21 \quad$ Id. at 402.

22 Actually, LCA specifically chose to use an LSAT/UGPA index, rather than LSAT scores or the UGPA separately, because they found that the "index correlates more highly with final law school GPA than either of its constituent measures,” LCA at 460-61. In other words, they bent over backward to give the benefit of the doubt to the "hard measures” of applicants’ qualifications.

23 See Tables 31, 33, and 35, in LCA at 478, 486, and 488.

24 In one of the models reported in Table 31, LCA at 478, there is a mildly statistically significant correlation between LSAT/UGPA and income, but it is
} 
is no mathematical reason why this should be surprising — no rule requires transitivity in statistical correlations-it is interesting that whatever it is that connects LSAT scores and UGPAs to law school grades is not correlated with that which connects law school grades with career success.

In short, the results in LCA are thought-provoking and powerful. Using the additional information available from the supplementary survey to investigate gender and family issues is a natural next step.

\section{B. Adding Information on Gender and Family Life: The Supplementary Questionnaire (SUPP)}

After gathering the data from the original PDS, Lempert and his co-authors realized that their data, while deep and rich, lacked information that would be particularly helpful in analyzing gender issues. Therefore, in 1999, they sent a one-page survey to everyone who had responded to the PDS. This "Supplementary Questionnaire” (SUPP) included six multi-part questions regarding the respondents' children (number and ages), weeks and hours worked in 1996 (the year covered by the original PDS), part-time and unemployed work status, attitudes about the effects of race and gender on their careers, and the gender and racial characteristics of their mentors. These responses were coded into forty separate variables, both continuous and categorical. A total of 703 usable responses were received (after excluding three responses with no gender listed).

Given these two surveys, and given the larger number of responses to the earlier

numerically quite minor. Also, no statistically significant correlations between these variables are visible in the other regressions. 
survey, one must choose between analyzing exclusively the cases that responded to both surveys or using the larger survey wherever possible. For example, to discuss results that rely on variables that were all in the original PDS, one could analyze all 1207 cases, whereas when the statistical tests involve any variables from the supplementary survey, results would only be possible for the smaller (but still substantial) number of cases.

To a large extent, this difference is unimportant here, because the bulk of the analyses below rely importantly on responses to the SUPP. However, where it does matter, only the smaller number of cases (i.e., the SUPP respondents) is analyzed, to maintain consistency. Thus, throughout this analysis, the basic dataset contains 703 cases. In particular regressions and averages, of course, the number of usable cases is less than 703, because not all respondents provided answers to every question. In addition, many of the results reported below use a variable called minority, which is a dummy variable with value 1 if the respondent is black, Hispanic (any race), or Native American, 0 if the respondent is white (non-Hispanic), and is coded as "missing" if the respondent is Asian. This excludes eighteen Asian respondents (10 male and 8 female) and follows LCA's choice in this regard. ${ }^{25}$

$25 \quad$ LCA at 399 n.5 (“Alumni of Asian heritage are excluded from most analyses for several reasons. They were present only in small numbers until the 1990s; as a group, they were not ordinarily considered in Michigan’s pre-1992 minority admissions program; and their status with respect to factors that distinguish the white and minority graduates we study is somewhat ambiguous. As applicants they typically had LSAT scores and UGPAs comparable with Michigan's white students, and as law students their 


\section{Statistical Issues in Comparing the Two Surveys}

When dealing with two survey populations, one of which is a subset of the other, it is essential to address issues regarding the comparability of the survey results. This section discusses a number of those issues. While the evidence suggests some reasons for concern, a comparison of the key statistical results in LCA with a replication of those results using only SUPP respondents suggests that such concerns might not be as serious as they first appear.

\section{Non-Response Bias Among Respondents to the Two Surveys}

LCA took great pains to ensure that the PDS dataset is an unbiased sample of all Michigan graduates, to ensure that responders were very much like non-responders on all crucial variables. For example, LCA sent out two sequential reminders, several months apart, to those who did not respond to the PDS. They also checked recipients' addresses to maximize the likelihood of connecting with all intended respondents. Unfortunately, this level of follow-up was not possible for the SUPP.

grade point averages were similar to those of white students and higher than the averages of most other minority students. Nonetheless, they were a visible ethnic minority at Michigan Law School and in the city of Ann Arbor, and they remain a visible minority in the world of law practice. Also some Asian alumni report the kinds of experiences and strains that are associated with minority status. Their small numbers preclude a separate examination of Asians before the 1990s, and their potential vulnerability to the strains minority group members face counsels against including them with the group of white students.”). 
One of LCA's central concerns, of course, was the possibility of non-response bias. ${ }^{26}$ That is, those who take the time to respond to surveys might differ in systematic ways from those who do not—perhaps being more motivated, more organized, etc.—and these differences could be correlated with law school and career success. Noting their disappointment in the overall $57 \%$ response rate, given all of their efforts at follow-up, ${ }^{27}$ LCA nonetheless concluded that “ $\ldots$ nonresponse bias does not appear to be a substantial problem in this dataset." ${ }^{28}$

To the extent, however, that there was even a small non-response bias among the PDS recipients, it is likely to be exacerbated in the SUPP. And even if the PDS has no non-response bias, the SUPP could introduce its own. For example, with only one mailing, it is again likely that only the most motivated graduates responded to the SUPP—although, interestingly, the minority graduates with the highest law school grades were the least likely to respond to the PDS, ${ }^{29}$ which suggests that motivation is not necessarily tied to classroom success. In some ways, this should not be surprising, because traits such as compulsiveness (which certainly correspond to the likelihood of responding to surveys) are not necessarily correlated with academic or professional success - indeed, they can work both in favor of and against an individual, depending on

\footnotetext{
$26 \quad$ See note 13 above.

27 See the methodological appendix, available from Lempert, at 9.

$28 \quad$ Id.

$29 \quad$ Id. at 11.
} 
how they manifest themselves. ${ }^{30}$

To check for any bias among the SUPP respondents, it is useful to look at when they returned the original PDS: $63.6 \%$ of those who responded to the initial PDS mailing also responded to the SUPP, while only $52.0 \%$ and $55.2 \%$ of those who responded to the PDS after the first and second reminders, respectively, responded to the SUPP. Thus, those who were the fastest to respond to the PDS were, as expected, more likely to respond to the SUPP than were those who responded only after one or two reminders. This suggests that the SUPP sample is not a random sample of the PDS pool of responders, and thus further analysis is appropriate.

The differences among PDS and SUPP respondents were much more significant along racial lines than gender. Indeed, the gender breakdowns of the PDS and SUPP response pools are nearly identical. The 1207 respondents to the PDS included 381 women (31.6\%) and 826 men (68.4\%), while the 703 SUPP respondents include 222 women (31.6\%) and 481 are men (68.4\%). ${ }^{31}$

However, there are important differences in the racial composition of the two groups of respondents, differences that potentially complicate the analysis. Among the

\footnotetext{
30 Clinical forms of these traits, such as obsessive-compulsive disorder, can become highly debilitating. See, for example, José A. YARYURA-TOBIAS, OBSESSIVECompulsive Disorder Spectrum: PATHOgenesis, Diagnosis, And Treatment (1997). 31 This is also very close to the gender breakdown of the 2144 recipients of the PDS (including nonrespondents), which included 700 women (32.6\%) and 1444 men (67.4\%).
} 
PDS’s 1207 cases, the breakdown was: 32.8\% black, 6.9\% Asian, 13.9\% Latino, 2.8\% Indian, and 43.6\% white. In the SUPP’s 703 cases, however, the breakdown was: $26.9 \%$ black, 5.7\% Asian, 11.5\% Latino, 2.6\% Indian, and 53.3\% white. Excluding Asians, as LCA did, from the definition of minority would result in $55.7 \%$ white and $44.3 \%$ minority in the SUPP, as opposed to $46.9 \%$ white and $53.1 \%$ minority for the PDS. Obviously, the SUPP's data come from a notably smaller proportion of minority respondents than did the data in the original PDS.

Looking at gender and race together, the proportions between women and men within each ethnic category are roughly the same for the two groups. For example, in the PDS, white men are $33.1 \%$ of the total, and white women are $10.5 \%$ of the total. In the SUPP dataset, white men are $39.4 \%$ of the total, and white women are $13.9 \%$. Therefore, white men outnumber white women by roughly three-to-one in both datasets, although the SUPP is slightly less male-dominated.

\section{Comparing Respondents to the Two Surveys}

One approach to understanding the differences between the two groups of respondents is to look at the means of the outcome variables (income, the index of service, and the career satisfaction index) for those who responded to the original PDS but not to the SUPP, as opposed to those who responded to both. The people who responded to the SUPP might be generally more successful, satisfied, etc. than those who responded to the original PDS. Looking at the three outcome variables, one can compute t-tests to determine whether the means between the two populations are statistically distinguishable.

The mean income of the 642 SUPP responders who reported their income on the 
PDS was slightly above $\$ 121,000$, while the mean of the 453 non-responders who had reported their 1996 income was slightly below $\$ 108,000$. These averages lend some support to the suspicion that people with more successful careers were more likely to respond to the SUPP. The tests in LCA and in this analysis, as noted earlier, used the log of income as a measure. Therefore, comparing the means of log income, a t-test indicated that one can reject the null hypothesis that the means are equal at greater than a 98\% level of confidence. For both service and satisfaction, the results were even stronger, with the null rejected at $99.9 \%$ and $99.8 \%$ levels of confidence, respectively. In each case, moreover, the differences in the means were in the direction that one would expect, i.e., SUPP responders were on average more satisfied with their careers and more likely to engage in service than non-responders, as well as earning higher incomes.

Tables 1 and 2 below present some descriptive statistics (means, medians, etc.) for the three outcome variables. Table 1 summarizes the alumni who did not respond to the SUPP, while Table 2 shows those who did. As these tables make clear, it is not just the means, but also the medians, that differ systematically. The medians for all outcome variables are higher for SUPP responders than the medians for non-responders. For example, the median for the SUPP responders is $\$ 7000$ higher than for the nonresponders (as opposed to a difference in means of $\$ 13,000+$ ).

For income and career satisfaction, moreover, the differences between the medians are smaller than the differences between the means, suggesting that the differences in means might have been somewhat exaggerated by some outliers. Interestingly, though, the difference between the medians for the service index is actually larger than the difference in means for that variable. 
Table 1: Descriptive Statistics for Non-Respondents to the SUPP

Did not Return SUPP

\begin{tabular}{|c|c|c|c|c|c|}
\hline & & $\begin{array}{c}\text { Income from } \\
\text { Job }\end{array}$ & Log Income & $\begin{array}{l}\text { service index } \\
\text { (high \# = } \\
\text { more service) }\end{array}$ & $\begin{array}{l}\text { career satisf } \\
\text { index (high \# } \\
=\text { very satisf) }\end{array}$ \\
\hline \multirow[t]{2}{*}{$\bar{N}$} & Valid & 463 & 453 & 507 & 458 \\
\hline & Missing & 978 & 988 & 934 & 983 \\
\hline \multicolumn{2}{|c|}{ Mean } & 107894.63 & 11.2973 & 5.45 & 40.96 \\
\hline \multicolumn{2}{|c|}{ Std. Error of Mean } & 6476.76 & 3.728E-02 & .22 & .41 \\
\hline \multicolumn{2}{|c|}{ Median } & 82000.00 & 11.3504 & 4.00 & 42.00 \\
\hline \multicolumn{2}{|c|}{ Mode } & 100000 & 11.51 & 1 & 48 \\
\hline \multicolumn{2}{|c|}{ Std. Deviation } & 139363.25 & .7935 & 4.89 & 8.80 \\
\hline \multicolumn{2}{|c|}{ Variance } & $1.942 \mathrm{E}+10$ & .6296 & 23.87 & 77.44 \\
\hline \multicolumn{2}{|c|}{ Minimum } & 0 & 6.21 & 0 & 12 \\
\hline \multicolumn{2}{|c|}{ Maximum } & 2000000 & 14.51 & 24 & 56 \\
\hline
\end{tabular}

Table 2: Descriptive Statistics for Respondents to the SUPP

Returned Supp

\begin{tabular}{|c|c|c|c|c|c|}
\hline & & $\begin{array}{c}\text { Income from } \\
\text { Job }\end{array}$ & Log Income & $\begin{array}{l}\text { service index } \\
\text { (high \# = } \\
\text { more service) }\end{array}$ & $\begin{array}{l}\text { career satisf } \\
\text { index (high \# } \\
=\text { very satisf) }\end{array}$ \\
\hline \multirow[t]{2}{*}{$\mathrm{N}$} & Valid & 655 & 642 & 702 & 632 \\
\hline & Missing & 48 & 61 & 1 & 71 \\
\hline \multicolumn{2}{|c|}{ Mean } & 121020.23 & 11.4176 & 6.61 & 42.56 \\
\hline \multicolumn{2}{|c|}{ Std. Error of Mean } & 5158.11 & 3.084E-02 & .19 & .30 \\
\hline \multicolumn{2}{|c|}{ Median } & 89000.00 & 11.4076 & 5.50 & 43.00 \\
\hline \multicolumn{2}{|c|}{ Mode } & 100000 & 11.51 & 3 & 42 \\
\hline \multicolumn{2}{|c|}{ Std. Deviation } & 132011.34 & .7814 & 5.01 & 7.64 \\
\hline \multicolumn{2}{|c|}{ Variance } & 1.743E+10 & .6105 & 25.10 & 58.30 \\
\hline \multicolumn{2}{|c|}{ Minimum } & 0 & 6.91 & 0 & 16 \\
\hline \multicolumn{2}{|c|}{ Maximum } & 2000000 & 14.51 & 22 & 56 \\
\hline
\end{tabular}

In short, the evidence suggests that the SUPP might be systematically biased in ways that the PDS was not. The discussion that follows, however, suggests that whatever those biases are, they do not affect the key statistical relationships that LCA emphasized in their analysis. 


\section{Congruence with Previous Results}

As noted earlier, LCA presented the results of four regression models for each of the three outcome variables in their study: income, career satisfaction, and service to the community. The most direct method of comparing the SUPP to the PDS, therefore, is to replicate those twelve regressions using only the SUPP respondents. If the results were substantially similar, then this would suggest that the differences between the respondent groups do not change the inferences that might be drawn from the SUPP. As the results below demonstrate, the results are, indeed, highly congruent with the regressions for the whole PDS sample.

Tables 3 and 4, on the following two pages, show the results for regressions in which logged income was the dependent variable. The independent variables for all four models include a constant term, years since graduation (and the same variable squared) ${ }^{32}$, sex/gender, age entering law school, the LSAT/UGPA index, and undergraduate major. The models then differ by whether they treat minority status as a single binary variable (white/minority) or as several group-specific variables, whether they include LSGPA, and whether they include variables for the respondent's current job sector.

Table 3 is a copy of Table 31 from LCA, ${ }^{33}$ showing their results for the four regression models. Table 4, on the other hand, shows the results for the same regressions

32 Using both the experience variable and its square, where their coefficients have the signs and sizes found in these regressions, depicts a relationship with income rising throughout life but at declining rates of increase.

LCA at 478. 
when only SUPP responders are included in the sample. The similarities between Tables 3 and 4 are, to say the least, substantial. Virtually every statistic in Table 4 is in the vicinity of those in Table 3. The variables that are statistically significant in Table 3 are almost all statistically significant in Table 4 . What differences do exist show no obvious pattern. Indeed, it might not be an exaggeration to say that an analyst reading LCA's descriptions of their results could look at Table 4 and barely notice a discrepancy.

Take first the question of statistical significance. In Models 1 and 1A, five explanatory variables are significant at the $95 \%$ level or higher in Table 3. In Table 4, only the Business/Economics major loses its statistical significance, while all four of the other variables are not only still statistically significant, but they are even significant at the same cutoff points (i.e., with the same number of asterisks). Even the change in the statistical power of the Business/Economics variable is relatively minor, since the coefficients in both Models 1 and 1A are still significant at the $90 \%$ level, though no longer at the $95 \%$ level.

In Models 2 and 2A, the first five variables are again significant at the same cutoff points on both tables. Interestingly, the white/minority variable becomes insignificant on Table 4, whereas it had been significant at the $95 \%$ level on Table 3. The point estimate, though, is still positive, although it is about a third smaller than the (already quite small) estimate in Table 3. The LSAT/UGPA index, which is numerically small and statistically insignificant in Model 2 on Table 3, is still numerically small but statistically significant in Model 2 on Table 4-and the estimates are unchanged in Model 2A. Further, the mild statistical significance of the humanities and business/economics majors (both, interestingly, tending to raise income above those of social science majors) in Table 3 
Table 3: OLS Regression Coefficients for Logged Income: PDS Results (LCA Table 31)

\begin{tabular}{|c|c|c|c|c|c|c|c|c|}
\hline & \multicolumn{2}{|c|}{ Model 1 (n = 969) } & \multicolumn{2}{|c|}{ Model 1A $(\mathrm{n}=1,033)$} & \multicolumn{2}{|c|}{ Model $2(n=969)$} & \multicolumn{2}{|c|}{ Model 2A $(\mathrm{n}=1,033)$} \\
\hline & $b$ & Std. Error & $b$ & Std. Error & $b$ & Std. Error & $b$ & Std. Error \\
\hline Constant & $10.870^{* * *}$ & .234 & $10.968 * * *$ & .232 & $9.767 * * *$ & .255 & $9.849 * * *$ & .251 \\
\hline Years since graduation & $.074 * * *$ & .013 & $.069 * * *$ & .012 & $.091^{* * *}$ & .012 & $.086 * * *$ & .011 \\
\hline Years since graduation squared & $-.001 * *$ & .000 & $-.001 *$ & .000 & $-.002 * * *$ & .000 & $-.002 * * *$ & .000 \\
\hline $\operatorname{Sex}(M=0, F=1)$ & $-.235 * * *$ & .053 & $-.207 * * *$ & .051 & $-.168 * *$ & .050 & $-.143^{* *}$ & .047 \\
\hline Age entering law school & -.013 & .008 & -.015 & .008 & $-.017 *$ & .007 & $-.018 *$ & .007 \\
\hline $\begin{array}{l}\text { Minority or white }(\mathrm{W}=0, \mathrm{M}= \\
\text { 1) }\end{array}$ & .067 & .072 & & & $.145 *$ & .067 & & \\
\hline \multicolumn{9}{|l|}{ Ethnicity (whites omitted) } \\
\hline Black & & & .027 & .078 & & & .109 & .073 \\
\hline Asian & & & .155 & .099 & & & .195 & .091 \\
\hline Latino & & & .074 & .084 & & & .137 & .078 \\
\hline Native American & & & .128 & .142 & & & .229 & .132 \\
\hline LSAT/UGPA index & .001 & .001 & .001 & .001 & -.001 & .001 & $-.002 *$ & .001 \\
\hline \multicolumn{9}{|l|}{$\begin{array}{l}\text { Undergraduate major (social } \\
\text { science omitted) }\end{array}$} \\
\hline Humanities & .091 & .058 & .077 & .055 & $.133^{*}$ & .053 & $.113^{*}$ & .051 \\
\hline Nat. Sci. & -.091 & .117 & -.075 & .112 & -.028 & .107 & -.026 & .103 \\
\hline Engineering & .090 & .129 & .158 & .116 & .026 & .119 & .089 & .107 \\
\hline Business/economics & $.176^{* *}$ & .065 & $.175^{* *}$ & .062 & $.136 *$ & .060 & $.135 *$ & .058 \\
\hline Other & -.016 & .097 & -.020 & .094 & -.023 & .089 & -.027 & .087 \\
\hline Final LSGPA & & & & & $.005^{* * *}$ & .001 & $.005^{* * *}$ & .001 \\
\hline \multicolumn{9}{|l|}{$\begin{array}{l}\text { Current job sector (private } \\
\text { practice omitted) }\end{array}$} \\
\hline Business/Finance & & & & & $.166^{* *}$ & .061 & $.158^{* *}$ & .058 \\
\hline Government & & & & & $-.339 * * *$ & .061 & $-.331 * * *$ & .059 \\
\hline Legal Svc/Pub Int & & & & & $-.607 * * *$ & .135 & $-.581 * * *$ & .131 \\
\hline Education & & & & & $-.608 * * *$ & .094 & $-.593 * * *$ & .090 \\
\hline Other & & & & & $-.385^{* * *}$ & .100 & $-.364 * * *$ & .095 \\
\hline
\end{tabular}


Table 4: OLS Regression Coefficients for Logged Income: SUPP Results

\begin{tabular}{|c|c|c|c|c|c|c|c|c|}
\hline & \multicolumn{2}{|c|}{ Model 1 (n = 599) } & \multicolumn{2}{|c|}{ Model 1A (n = 628) } & \multicolumn{2}{|c|}{ Model $2(n=585)$} & \multicolumn{2}{|c|}{ Model 2A $(\mathrm{n}=611)$} \\
\hline & $B$ & Std. Error & $b$ & Std. Error & $b$ & Std. Error & $b$ & Std. Error \\
\hline Constant & $10.819 * * *$ & .310 & $10.845^{* * *}$ & .309 & $9.896 * * *$ & .328 & $9.901 * * *$ & .325 \\
\hline Years since graduation & $.081 * * *$ & .017 & $.077 * * *$ & .016 & $.102 * * *$ & .016 & $.099 * * *$ & .015 \\
\hline Years since graduation squared & $-.002 * *$ & .001 & $-.001 *$ & .001 & $-.002 * * *$ & .001 & $-.002 * * *$ & .001 \\
\hline $\operatorname{Sex}(M=0, F=1)$ & $-.285 * * *$ & .068 & $-.280 * * *$ & .066 & $-.201^{* *}$ & .063 & $-.186^{* *}$ & .062 \\
\hline Age entering law school & -.010 & .0010 & -.010 & .010 & $-.020 *$ & .010 & $-.020 *$ & .010 \\
\hline $\begin{array}{l}\text { Minority or white }(\mathrm{W}=0, \mathrm{M}= \\
\text { 1) }\end{array}$ & .042 & .091 & & & .102 & .085 & & \\
\hline \multicolumn{9}{|l|}{ Ethnicity (whites omitted) } \\
\hline Black & & & .036 & .101 & & & .105 & .094 \\
\hline Asian & & & .099 & .141 & & & .231 & .134 \\
\hline Latino & & & -.003 & .110 & & & .043 & .102 \\
\hline Native American & & & .216 & .178 & & & .255 & .162 \\
\hline LSAT/UGPA index & .001 & .001 & .001 & .001 & $-.002 *$ & .001 & $-.002 *$ & .001 \\
\hline \multicolumn{9}{|l|}{$\begin{array}{l}\text { Undergraduate major (social } \\
\text { science omitted) }\end{array}$} \\
\hline Humanities & .043 & .073 & .034 & .071 & .101 & .067 & .086 & .066 \\
\hline Nat. Sci. & -.166 & .152 & -.148 & .146 & -.056 & .139 & -.061 & .135 \\
\hline Engineering & .036 & .163 & .115 & .151 & -.067 & .152 & .021 & .141 \\
\hline Business/economics & .150 & .082 & .136 & .079 & .126 & .075 & .122 & .073 \\
\hline Other & .101 & .124 & .108 & .121 & .092 & .114 & .105 & .112 \\
\hline Final LSGPA & & & & & $.005^{* * *}$ & .001 & $.005^{* * *}$ & .001 \\
\hline \multicolumn{9}{|l|}{$\begin{array}{l}\text { Current job sector (private } \\
\text { practice omitted) }\end{array}$} \\
\hline Business/Finance & & & & & $.155^{*}$ & .078 & $.160^{*}$ & .076 \\
\hline Government & & & & & $-.411 * * *$ & .074 & $-.403 * * *$ & .072 \\
\hline Legal Svc/Pub Int & & & & & $-.537 * *$ & .173 & $-.534 * *$ & .171 \\
\hline Education & & & & & $-.487 * * *$ & .118 & $-.465 * * *$ & .113 \\
\hline Other & & & & & $-.514^{* * *}$ & .134 & $-.479 * * *$ & .131 \\
\hline
\end{tabular}


goes away in Table 4. On the other hand, the statistical significance of the LSGPA variable (discussed above), as well as the job sector variables, is almost completely unchanged (with the Business/Finance sector dropping to the 95\% level of significance in Table 4).

Moving from statistical significance to the signs of the point estimates, only the “other” undergraduate major changes sign in all four models from Table 3 to Table 4 . In Model 1A, the "Latino" variable changes signs, while the "Engineering” variable switches signs in Model 2. No other variables change sign in Model 2A. None of these variables are statistically significant on either table.

Finally, the size of the coefficients is remarkably similar. The only coefficients that change by a proportionally large amount, such as "Engineering” on Model 2A, are statistically very insignificant (in that specific instance, with a p-value of 0.883). ${ }^{34}$

In short, concerns about the comparability of the SUPP respondents to the entire PDS respondent population, while certainly important to consider, appear not to affect the regression results that LCA present. The congruence between results provides some measure of confidence that analysis of the SUPP data is not meaningfully compromised by non-response bias.

34 Analyses of the satisfaction and service regressions, comparing SUPP-only results to LCA’s Tables 33 and 35, showed very similar patterns to those discussed here with regard to the income variable. Therefore, those results are not reproduced or discussed here. 


\section{How Do Gender and Family Status Affect Earnings?}

Having considered (and tentatively set aside) concerns about potential bias in the SUPP dataset, it is possible to proceed with an analysis of some questions not raised in LCA that are now estimable using SUPP data. This section discusses regression results for models of the effects of gender and child rearing on income, work status, and hours worked.

\section{A. Income, Gender, and Child-Rearing}

The first set of statistical tests investigates the determinants of income, looking specifically at the effects of gender and being a parent (and how those effects interact). These effects are rather difficult to isolate, but the results are quite interesting.

Initial regressions were in the following form:

$$
\log y=\mathrm{a}+\mathrm{b}_{1} \text { sex }+\mathrm{b}_{2} \text { anykids }+\mathrm{b}_{3} \text { ageyoung }+\mathrm{c} Z \text {, }
$$

where $y=$ income, sex $=1$ for women and 0 for men, anykids is a dummy variable equal to 1 if the respondent has any children and zero otherwise, ageyoung is the age of the respondent's youngest child, and $Z$ represents all other explanatory variables. ${ }^{35}$ In this

35 The timing differences between the PDS and the SUPP created some difficulty in constructing several of the variables. The incomes reported from the PDS were for 1996, whereas the numbers and ages of children from the SUPP were for January 1998.

Therefore, the data on children needed to be adjusted for the passage of time.

Fortunately, the SUPP also asked about ages of children, so the numbers and ages of children could be adjusted appropriately. This issue does not arise for the analyses of 
form, the results for $b_{2}$ or $b_{3}$ showed no statistically significant effects for anykids or ageyoung. ${ }^{36}$ This could, however, be because having children (especially very young children) effects women and men quite differently. If so, because the estimates for $b_{2}$ and $b_{3}$ mix together men and women, with $b_{1}$ merely picking up any effect due solely to sex (but not children), the estimates would not capture the important relationships.

To correct for this, a new set of regressions took the following form:

$$
\log y=\mathrm{a}+\mathrm{b}_{1} \text { sex }+\mathrm{b}_{2} \text { anykids }+\mathrm{b}_{3} \text { femkids }+\mathrm{b}_{4} \text { ageyoung }+\mathrm{b}_{5} \text { femagey }+\mathrm{cZ},
$$

where femkids is the product of the sex variable and the anykids variable, and femagey is the product of the sex variable and the ageyoung variable. (femkids $=1$ if the respondent is a woman with children, zero otherwise. femagey is positive if the respondent is a woman with children, zero otherwise.) Presumably, then, $\mathrm{b}_{2}$ would say whether or not having children has an effect on income, and $b_{3}$ would say whether or not being a woman and having children affects income differently, with similar interpretations of $b_{4}$ and $b_{5}$.

work status, below, because those data (unlike income) were reported on the SUPP in response to a question that specifically asked for work status in January 1998, the same month as the data regarding children. The issue does arise again, however, in the hours worked section, because the SUPP specifically asks about respondents' hours worked in 1996.

36 These preliminary results are not presented here in tabular form. 


\section{Table 5: Income, Sex, and Children}

Interaction Between Sex/Gender and Having Children, on Inconie

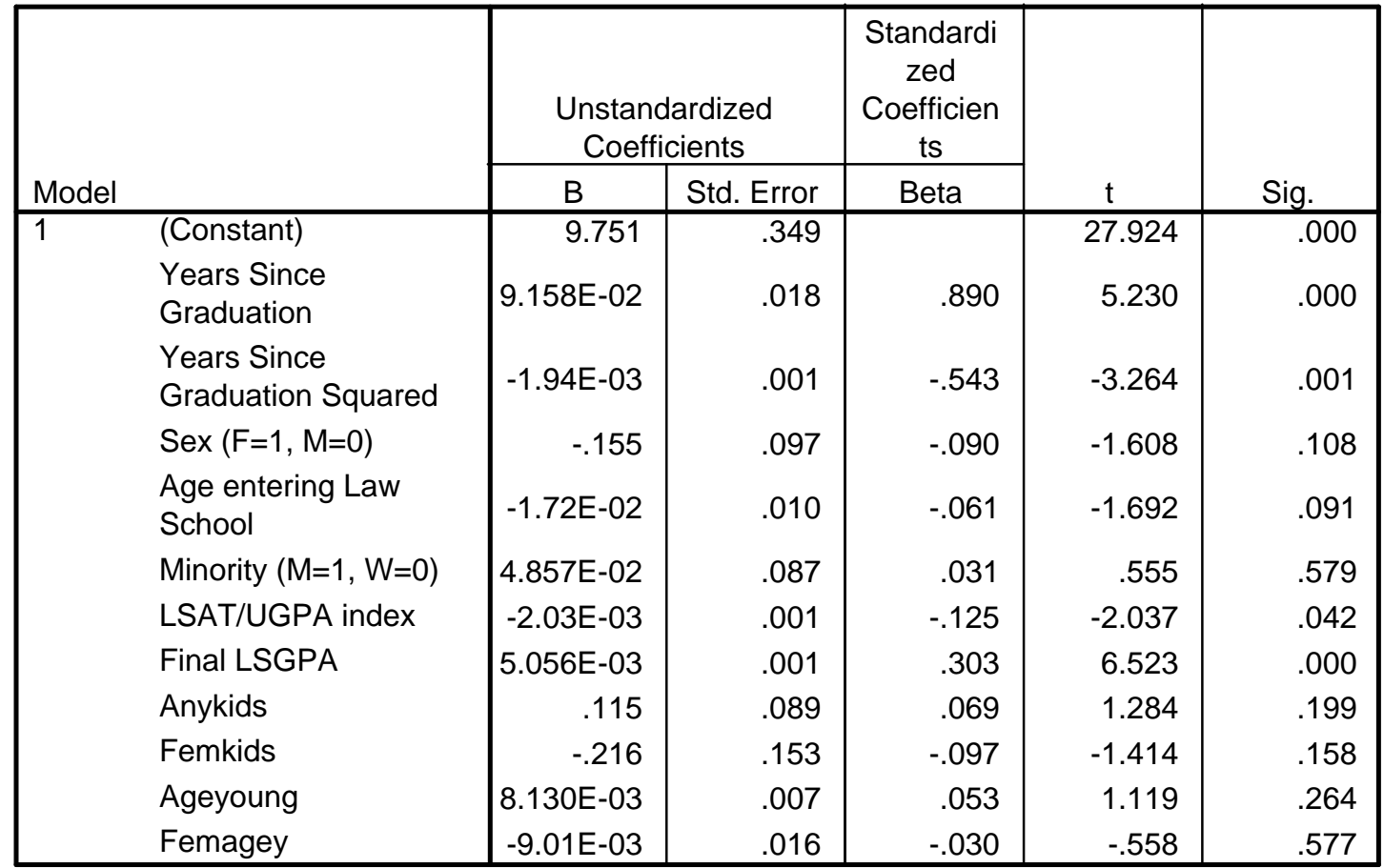

a. Dependent Variable: natural log of resp's income (v57)

The results of such a regression are shown in Table 5 above. In that regression, $b_{2}$ and $b_{3}$ had p-values ("Sig." on the tables) of slightly less than 0.2 , which is substantially above the typical cutoffs for statistical significance. The point estimates, though, suggest an interesting story. If those estimates $\left(b_{2}=0.115\right.$ and $\left.b_{3}=-0.216\right)$ were reliable, they would imply that having children raises one's income by $11.5 \%$, whereas being a woman and having children lowers income by $21.6 \%$. Together, these estimates imply that being a woman with children lowers income by about $10 \%$ net (after adding $b_{2}$ and $b_{3}$ together). ${ }^{37}$ In blunt terms, men gain from being dads, and women lose from being

37 Since the dependent variable is $\log y$, the interpretation of the coefficients on nonlogarithmic independent variables is that a unit change in the independent variable 
moms.

Those point estimates are, however, not statistically significant. Moreover, the estimates for $\mathrm{b}_{4}$ and $\mathrm{b}_{5}$ were statistically insignificant and numerically minuscule (less than one-tenth the magnitude of $b_{2}$ and $b_{3}$ ), suggesting somewhat counter-intuitively that the ages of children do not affect earnings. Dropping ageyoung and femagey from the regression, therefore, the regression takes the following form:

$$
\log y=\mathrm{a}+\mathrm{b}_{1} \text { sex }+\mathrm{b}_{2} \text { anykids }+\mathrm{b}_{3} \text { femkids }+\mathrm{c} Z \text {. }
$$

The results, shown in Table 6 below, show both $b_{2}$ and $b_{3}$ at or near a $5 \%$ p-value, with point estimates $b_{2}=0.155$ and $b_{3}=-0.265$, which are very similar to the previous result, giving a net penalty of $11 \%$ for women with children. Again, having children seems to raise men's income and lowers women's income.

The analysis summarized in Tables 5 and 6 looks at whether the respondent has any children, no matter where those children are living. The data from the SUPP, however, also permits one to focus only on the effects of having children living with the respondent, which is certainly relevant for divorced and separated parents. If child rearing affects income, then there should be something unique about having children living at home.

leads to a b\% change in y. Since the result is in decimal form, a coefficient of 0.115 is $11.5 \%$. 


\section{Table 6: Income, Sex, Children (age variables excluded)}

Interaction Between Sex/Gender and Having Children, on Income, exluding Ageyoung and Femagey

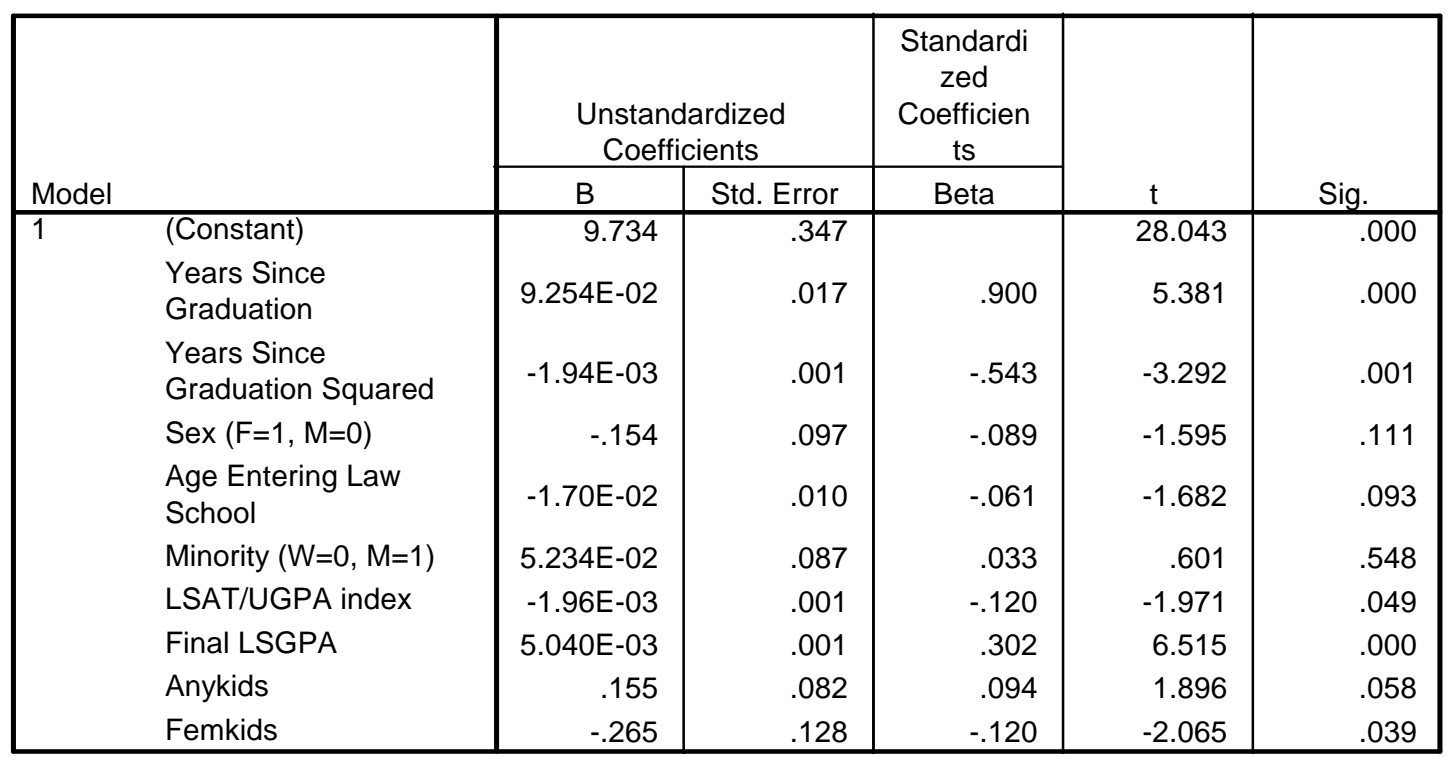

a. Dependent Variable: natural log of resp's income (v57)

Changing the anykids variable and the femkids variable to include only children living with the parent, the regressions now use the variable anywith, which equals one if the respondent has any children living with them and zero otherwise, and femwith, which is the product of female and anywith (so that it equals one if the respondent is a woman who has children living with her). ${ }^{38}$ Therefore, the analogous regression to that reported

38 Similarly, the variables ageyoung and femagey should be replaced with variables that include the ages of only those children living with the respondent. However, attempts to use such variables in the regression were rejected by the estimation program (SPSS), because the variables are too closely correlated with the anywith and femwith variables. Therefore, Table 7 reports regression results for an equation using ageyoung and femagey, which serve as instruments for the "living with" alternatives. Given these 
in Table 5 is:

$$
\log y=\mathrm{a}+\mathrm{b}_{1} \text { sex }+\mathrm{b}_{2} \text { anywith }+\mathrm{b}_{3} \text { femwith }+\mathrm{b}_{4} \text { ageyoung }+\mathrm{b}_{5} \text { femagey }+\mathrm{c} Z \text {. }
$$

These results are summarized in Table 7 below. As before (in Table 5), this regression produced statistically significant estimates for $b_{2}$ and $b_{3}$, while $b_{4}$ and $b_{5}$ continued to be completely insignificant and extremely small.

\section{Table 7: Income, Sex, and Children Living at Home}

Interaction Between Sex/Gender and Having Children at Home, on Incomfe

\begin{tabular}{|c|c|c|c|c|c|c|}
\hline \multirow{2}{*}{\multicolumn{2}{|c|}{ Model }} & \multicolumn{2}{|c|}{$\begin{array}{c}\text { Unstandardized } \\
\text { Coefficients }\end{array}$} & \multirow[t]{2}{*}{$\begin{array}{c}\begin{array}{c}\text { Standardi } \\
\text { zed }\end{array} \\
\begin{array}{c}\text { Coefficien } \\
\text { ts }\end{array} \\
\text { Beta } \\
\end{array}$} & \multirow[b]{2}{*}{$\mathrm{t}$} & \multirow[b]{2}{*}{ Sig. } \\
\hline & & $\mathrm{B}$ & Std. Error & & & \\
\hline \multirow[t]{12}{*}{1} & (Constant) & 9.737 & .345 & & 28.187 & .000 \\
\hline & $\begin{array}{l}\text { Years since } \\
\text { graduation }\end{array}$ & 8.873E-02 & .018 & .863 & 5.064 & .000 \\
\hline & $\begin{array}{l}\text { Years since } \\
\text { graduation squared }\end{array}$ & $-1.79 E-03$ & .001 & -.501 & -2.973 & .003 \\
\hline & $\operatorname{Sex} F=1, M=0)$ & -.141 & .085 & -.081 & -1.652 & .099 \\
\hline & $\begin{array}{l}\text { Age Entering Law } \\
\text { School }\end{array}$ & $-1.74 \mathrm{E}-02$ & .010 & -.062 & -1.736 & .083 \\
\hline & Minority $(w=0, m=1)$ & 6.049E-02 & .087 & .038 & .694 & .488 \\
\hline & LSAT/UGPA index & $-1.99 \mathrm{E}-03$ & .001 & -.122 & -2.009 & .045 \\
\hline & Final LSGPA & 5.096E-03 & .001 & .305 & 6.609 & .000 \\
\hline & Anywith & .211 & .094 & .133 & 2.244 & .025 \\
\hline & Femwith & -.408 & .168 & -.169 & -2.425 & .016 \\
\hline & Ageyoung & $-1.03 E-03$ & .009 & -.007 & -.117 & .907 \\
\hline & Femagey & 8.517E-03 & .018 & .028 & .467 & .641 \\
\hline
\end{tabular}

a. Dependent Variable: natural log of resp's income (v57)

correlations, it is not surprising that the results in Tables 6 and 8 are statistically more powerful than those in Tables 5 and 7, since the age variables provide so little additional information. 
Finally, as shown in Table 8, dropping ageyoung and femagey to run an analogous regression to that in Table 6:

$$
\log y=\mathrm{a}+\mathrm{b}_{1} \text { sex }+\mathrm{b}_{2} \text { anywith }+\mathrm{b}_{3} \text { femwith }+\mathrm{c} Z
$$

produces highly significant estimates for both $b_{2}$ and $b_{3}$, with p-values below 0.01 for

each. The point estimates are even larger than before (in Table 6), with $b_{2}=0.202$ and $b_{3}$ $=-0.356$. Since $b_{2}+b_{3}=-0.154$, being a woman living with children lowers income by $15.4 \%$.

\section{Table 8: Income, Sex, and Children Living at Home (age variables excluded)}

Interaction Between Sex/Gender and Having Children ă Home, on Income, exluding Ageyoung and Femagey

\begin{tabular}{|c|c|c|c|c|c|c|}
\hline \multirow[b]{2}{*}{ Mod } & & \multicolumn{2}{|c|}{$\begin{array}{c}\text { Unstandardized } \\
\text { Coefficients }\end{array}$} & \multirow[t]{2}{*}{$\begin{array}{c}\begin{array}{c}\text { Standardi } \\
\text { zed } \\
\text { Coefficien } \\
\text { ts }\end{array} \\
\text { Beta }\end{array}$} & \multirow[b]{2}{*}{$\mathrm{t}$} & \multirow[b]{2}{*}{ Sig. } \\
\hline & & B & Std. Error & & & \\
\hline \multirow[t]{10}{*}{1} & (Constant) & 9.721 & .342 & & 28.447 & .000 \\
\hline & $\begin{array}{l}\text { Years since } \\
\text { graduation }\end{array}$ & 8.984E-02 & .017 & .873 & 5.180 & .000 \\
\hline & $\begin{array}{l}\text { Years since } \\
\text { graduation squared }\end{array}$ & $-1.82 \mathrm{E}-03$ & .001 & -.510 & -3.057 & .002 \\
\hline & $\operatorname{Sex}(F=1, M=0)$ & -.140 & .085 & -.081 & -1.648 & .100 \\
\hline & $\begin{array}{l}\text { Age entering law } \\
\text { school }\end{array}$ & $-1.71 E-02$ & .010 & -.061 & -1.713 & .087 \\
\hline & Minority $(w=0, m=1)$ & 6.144E-02 & .087 & .039 & .708 & .479 \\
\hline & LSAT/UGPA index & $-2.01 E-03$ & .001 & -.123 & -2.028 & .043 \\
\hline & Final LSGPA & $5.105 \mathrm{E}-03$ & .001 & .306 & 6.633 & .000 \\
\hline & Anywith & .202 & .071 & .128 & 2.845 & .005 \\
\hline & Femwith & -.356 & .124 & -.148 & -2.878 & .004 \\
\hline
\end{tabular}

a. Dependent Variable: natural log of resp's income (v57)

It is also interesting that in all four of these regressions, the p-value for $b_{1}(\operatorname{sex})$ is approximately 0.10 or higher, whereas it had been roughly 0.05 for all four models in Table 3 (LCA’s Table 31) and between 0.068 and 0.062 in Table 4. Although it might be reading too much into such a small change, this difference adds to the impression that the 
income penalty that women pay is tied to having children, not to being a woman per se. ${ }^{39}$

That is, there are four relevant groups: mothers, fathers, childless men, and childless women. The results of the regressions reported above suggest either that all four groups fare differently, or (because the estimates for the coefficient of the sex variable are not statistically significant at the $95 \%$ level $^{40}$ ) at least that fathers do betterand mothers do worse - than the childless (no matter what their sex).

For example, the results suggest that fathers make more money than childless men, because the coefficients on anykids (Table 6) and anywith (Table 8) are positive. That is, since the values of the binary variables sex and femwith are zero for all men (both fathers and childless men), neither group suffers the income penalties associated with those variables. ${ }^{41}$ In addition, though, fathers gain an income bonus from anykids and anywith, because their value for those variables is 1 , whereas for childless men anykids and anywith are equal to 0 .

These results, while quite interesting, certainly call for further exploration. index variable becomes statistically significant (at the 95\% level)—unlike in three of the four models in Table 3-and negative (albeit quite small), meaning that the "hard admissions criteria” actually correlate with slightly lower income.

40 Those estimates in Tables 6 and 8 have p-values of 0.111 and 0.100 , respectively. 41 Even if the sex variable is considered to be statistically unreliable, the key here is that fathers do better than childless men because of the significant coefficients on anykids or anywith. 
Previous research by David Chambers, ${ }^{42}$ for example, indicates that there is an income bonus for men when they become fathers, but that mothers are not separately penalized. Similarly, a separate study of Michigan’s law graduates concluded: “[O]ver $40 \%$ of the difference [in income] in our population can be attributed, directly or indirectly, to parenting. But once we control for sex differences in labor supply and work history, mothers earn no less than do childless women, while both groups of women earn less than men."43 Both of those studies, therefore, suggest that fathers do better than everyone else, and both leave open the possibility that men in general do better than women. $^{44}$

Several competing explanations of this phenomenon are possible. Men who become fathers might feel more obligated to raise their incomes. Alternatively, the causality could work in the opposite direction, with men who have achieved certain income levels deciding that it is time to have children. A cynical explanation is also possible, wherein men with children hide in their offices to shirk child-rearing duties, thus raising their income only coincidentally. No matter the explanation, though, the

David L. Chambers, Accommodation and Satisfaction—Women and Men Lawyers and the Balance of Work and Family, 14 L. \& Soc. INQUIRY (1989) (finding that men with children earned more than those without children, and more than women with or without children).

43 Robert G. Wood et al., Pay Differences Among the Highly Paid: The MaleFemale Earnings Gap in Lawyers’ Salaries, 11 J. LABOR ECON. 417, 439 (1993) 44 In addition, Professor Lempert ran separate regressions on SUPP data for men and women, finding somewhat statistically significant evidence that the fathers earned more than the childless men, but that mothers earned no less than childless women. 
results here do suggest that being a father is correlated with higher income.

These results are unique, therefore, in finding both an income bonus for fathers and an income penalty for mothers-and possibly (at a 90\% level of statistical significance) that women do worse, as women, than men do. Clearly, further work should address whether there are really different results for these four categories of lawyers, or whether it is only men who benefit financially from being fathers. The analyses below approach these issues from a different direction.

\section{B. Work Status: Full-Time, Part-Time, and Not Employed}

The discussion in this section centers on the work status of Michigan's law graduates. On the SUPP, respondents reported their work status as “full time," "parttime,” or "not employed.” 45 The survey did not provide definitions or guidelines for determining the cutoff point between full-time and part-time status, which forced the

respondents to rely on their own sense of what constitutes full-time work. ${ }^{46}$ Responses to

45 This question on the SUPP asks for employment status in January 1998. For those who describe themselves as part-time or not employed, the questionnaire gives them the option of describing why they are not working full time. The list (from which respondents can choose one or more reasons) includes: "in order to care for children,” “due to ill health or disability," "due to (partial) retirement," or "for other reasons (please specify)” (emphasis on survey).

46 Unfortunately, it is not possible to determine what respondents' consider to be full-time and part-time work, because the previous question on the SUPP asks about hours worked during calendar year 1996, whereas the work status question asks about 
this question generated two binary dependent variables: non_ft, or “non-full-time,” which combines the part-timers and the unemployed together with a value of 1 (and full-time workers coded with a zero), and parttime, which codes the unemployed as missing variables (such that the regressions using this dependent variable will differentiate between working full-time or part-time). The regressions below, with one exception, focus on the parttime variable.

\section{$\underline{\text { A Note Regarding Binary Dependent Variables }}$}

The use of binary dependent variables (also known as limited dependent variables or dummy dependent variables) introduces some unique statistical issues not faced when the dependent variable is continuous. For example, when using income as the dependent variable, it is possible to interpret coefficients on explanatory variables as describing the marginal impact of a change in the explanatory variable on the dependent variable. Thus, if income is regressed on years of education and other variables, a coefficient estimate of

work status in January 1998. (Cf. note 35 above.) Thus, it is easy to imagine that someone who is part-time or not employed in 1998 could have been working full-time in 1996. If, however, there is any persistence to work status, it is notable that the 1998 nonfull-timers reported working significantly less than 2000 total hours in 1996. Those nonfull-timers averaged fewer than 1000 hours of work in 1996, whereas the self-described full-timers averaged over 2300 hours. Over two-thirds of the non-full-timers had worked fewer than 2000 hours in 1996—although the highest self-reported hours in 1996 for the entire sample (4420) came from someone who was not employed in 1998. The culture in some law firms, by many informal reports, would view 2300 hours as part-time. 
500 on the education variable would imply that a one-year increase in education is correlated with a $\$ 500$ increase in earnings. For binary dependent variables, however, this is not sensible, because the dependent variable only takes on values of zero or one. Thus, if we regress a binary variable like high school graduation on several variables, an estimated coefficient of 0.3 cannot be directly interpreted as meaning, "A one unit increase in this variable will increase a person's quantity of high school graduation by 0.3 units.” The logical inferences for binary dependent variables are, therefore, different than those for continuous dependent variables.

The two most common estimation techniques for binary dependent variables are the Linear Probability Model ${ }^{47}$ and the Binomial Logit Model. ${ }^{48}$ The advantage of the former, which relies on ordinary least squares regression, is that the estimated coefficients can simply be interpreted as probabilities. That is, if the coefficient on an explanatory variable is estimated to be 0.25 , then a one unit increase in that explanatory variable is associated with a $25 \%$ increase in the probability of the binary dependent variable being true. If the explanatory variable is itself binary, such as "female," then this simply means that being female raises the probability of the dependent variable being true by $25 \%$.

The limitation of the Linear Probability Model is that it does not constrain the results to be within the $0-100 \%$ range. That is, it allows for a prediction of more than a

\footnotetext{
47 A. H. STUDENMUND, Using ECONOMETRICS 434-42 (4th Ed. 2001).

$48 \quad$ Id. at $442-48$.
} 
100\% probability that the dependent variable will be true. ${ }^{49}$ Therefore, the Binomial Logit Model was designed specifically to keep probabilities within the meaningful range-with the significant cost that the coefficient estimates are no longer intuitively meaningful. Instead, the estimates are the "log of the odds of the dependent variable being equal to one.”50

Statistical theorists continue, of course, to develop new models for binary dependent variables. ${ }^{51}$ Even so, Linear Probability and Binomial Logit Models are still preferred to the "state of the art" in estimating models with binary dependent variables, because the emerging alternatives_-nonparametric estimation and semiparametric estimation—are potentially even more problematic. Nonparametric estimation is worse when, as in the work based on the PDS and the SUPP, the number of explanatory variables is large, while semiparametric estimation is still in the experimental stage.

There is, moreover, still general agreement that Binomial Logit Models are better than the Linear Probability Model (again, because logistic estimation limits the predicted probability values to the range between 0 and 1 ). However, logistic models can be easily misspecified and lead to poor predictions.

For the analyses of the work status variables, therefore, it was necessary to run

$49 \quad$ Id. at 436.

$50 \quad$ Id.

51 This discussion is based on: Joel L. Horowitz \& N.E. Savin, Binary Response Models: Logits, Probits, and Semiparametrics, 15 J. ECON. PERSPECTIVES, Fall 2001, at 46. 
regressions in both the Linear Probability and Binomial Logit forms. Comparing the results for statistical significance, none of the tested relationships showed any meaningful difference between the two estimation techniques. Therefore, the tables below report results from the Linear Probability Model regressions, because the results are easily interpreted as probability values.

\section{Full-Timers, Part-Timers, and Not Employed in the Supplementary Questionnaire}

Looking at the responses to the work status question on the SUPP, it becomes clear that these data are quite suggestive (although, as discussed below, they can be of only limited value for regression analysis). As Table 9 shows, only 21 out of 703 SUPP respondents identified themselves as Not Employed, while another 39 identified themselves as Part-Time, meaning that 643 (or 91.5\% of the sample) called themselves full time workers. Michigan's law school graduates generally work full time, which is hardly surprising.

Not included on Table 9, but interesting nonetheless, are the reasons given for being part-time workers or for not being employed. Among the 39 part-timers, 24 listed childcare, 2 listed health reasons, 3 listed partial retirement, and 14 chose "other."

(Multiple responses were allowed.) Among the 21 respondents who were not employed, 10 reported childcare as a reason, none reported health, 3 said they were retired, and 9 chose "other." Clearly, childcare is a major part of the story here.

It is, therefore, interesting that 30 of the 39 part-timers are women, and 17 of the 21 not employed respondents are women — especially since more than twice as many SUPP respondents are men (481 to 222). Table 10 breaks down the job status results by 
sex/gender and marital status. ${ }^{52}$ On this table, there are again 39 total part-timers, of whom 30 are women, but only 20 unemployed, 16 of whom are women, because one of the unemployed respondents had an invalid or missing response to the marital status question. Twenty-six of the 30 part-time women are married or remarried, as are 14 of the 20 unemployed women.

Table 9: Employment Status in January 1998

employment status Jan98

\begin{tabular}{|ll|r|r|r|r|}
\hline & & & & $\begin{array}{c}\text { Cumulative } \\
\text { Percent }\end{array}$ \\
\hline Valid & Full-time & 643 & 30.0 & 91.5 & 91.5 \\
& Part-time & 39 & 1.8 & 5.5 & 97.0 \\
& Not & 21 & 1.0 & 3.0 & 100.0 \\
& Employed & 703 & 32.8 & 100.0 & \\
& Total & 1441 & 67.2 & & \\
Missing & 9 & 2144 & 100.0 & & \\
Total & & & & \\
\hline
\end{tabular}

52 Although these totals do not appear directly in Table 10, out of 696 valid responses to the SUPP, 199 did not report being currently married (never married, divorced and not remarried, widowed and not remarried, and other). Thus, 28.6\% were unmarried. By comparison, in the original PDS, out of 1195 valid responses, only 384 were not married (285 never married, 90 divorced and not remarried, 1 widowed and not remarried, and 8 "other"). This is 32.1\% of the PDS respondents. This was true for the older (pre1990) grads, although many more of the nineties graduates obviously had never married. SUPP respondents were, therefore, somewhat more likely to be married than PDS respondents. 


\section{Table 10: Gender, Marital Status, and Work Status}

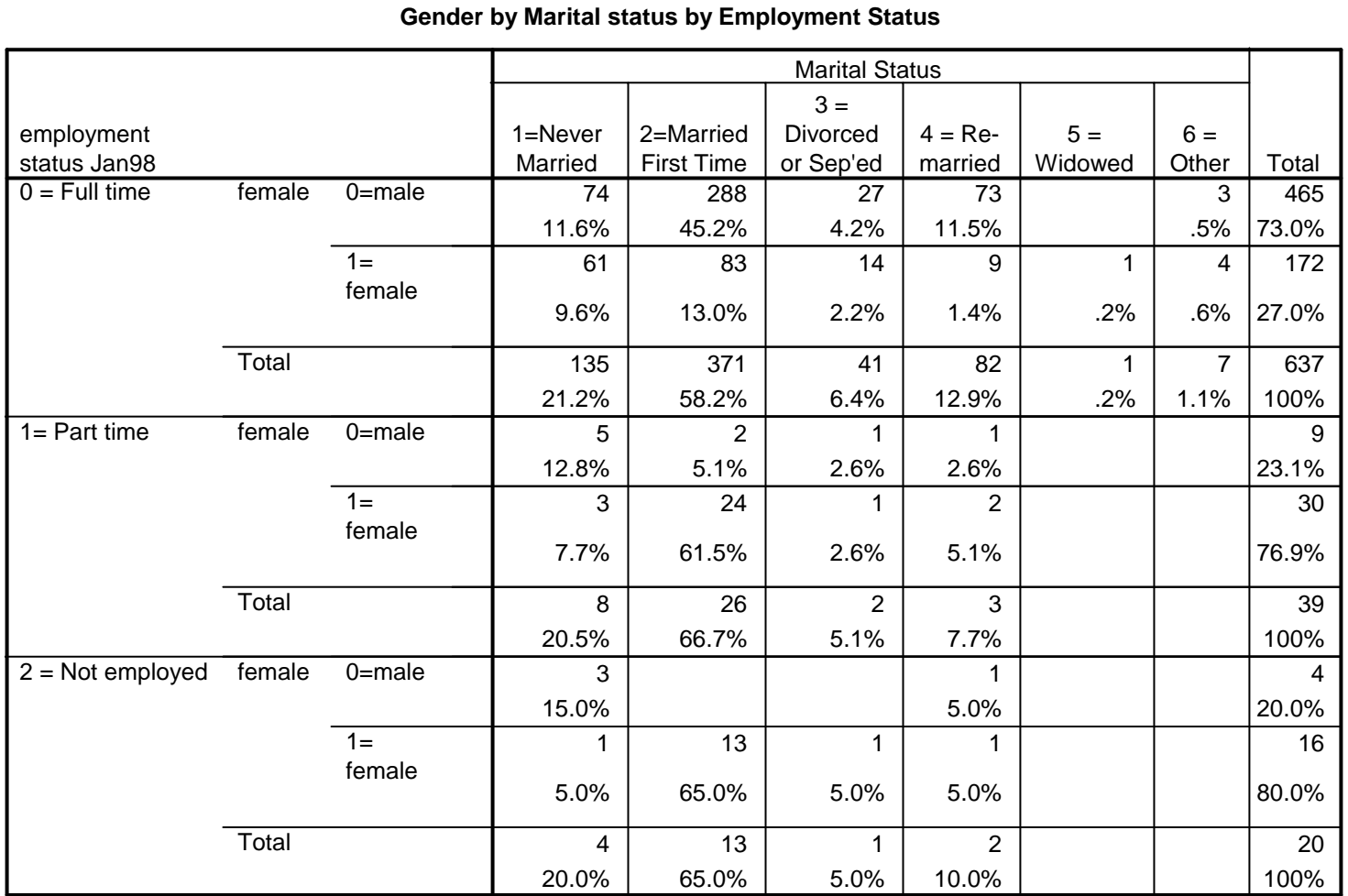

These tables suggest a very gendered story about work status. Unfortunately, regressions with the work status variables (non_ft and parttime) as the dependent variable cannot be very powerful, because the extreme limits on the number of cases mean that the regression analyses must draw inferences from only a few dozen respondents who do not work full time. Even so, it makes sense to run some regressions on these limited data, at least to begin to get a sense of the relationships involved. ${ }^{53}$ Because of the limited extensive alumni survey. When that is available, if it contains a larger number of part- 
numbers of part-timers and unemployed respondents, the final section of the paper below looks at "hours worked" instead of employment status, which also has the advantage of being a continuous variable, making the binary dependent variables issues (discussed above) moot.

Given these data limitations, it is best to begin with two very basic regressions, with employment status (parttime and non_ft) as the dependent variables and gender, experience (“yrs grad to PDS”), ${ }^{54}$ and the interaction between gender and age as independent variables.

The results in Table 11 show that being a woman significantly affects being nonfull-time. (It is both statistically significant and numerically large, showing that being a woman makes a respondent $14 \%$ more likely to be non-full-time.) The interactive coefficient is, at best, marginally statistically significant, and it is numerically very small. Virtually the same result holds true for the linear regression with parttime as the dependent variable, in Table 12, with the female variable being highly statistically significant and numerically important (whereas the interactive variable is now completely insignificant). With the regressions for these equations as Binomial Logit Models, the significance levels were similar for all variables, meaning that being a woman is the only one of these three variable that appeared to correlate with part-time or unemployed status.

timers and unemployed, the questions investigated here can be tested against that larger dataset.

54 Note that the regression results in all of the remaining tables display descriptions of the explanatory variables, rather than the shorter variable names. 


\section{Table 11: Non-Full-Time status, Gender, and Work Experience}

Non-Full Time Status vs. Gender, Experience, and Gender/Experience Interactiôn

\begin{tabular}{|c|c|c|c|c|c|c|}
\hline \multirow[b]{2}{*}{ Model } & & \multicolumn{2}{|c|}{$\begin{array}{c}\text { Unstandardized } \\
\text { Coefficients }\end{array}$} & $\begin{array}{l}\text { Standardi } \\
\text { zed } \\
\text { Coefficien } \\
\text { ts }\end{array}$ & \multirow[b]{2}{*}{$\mathrm{t}$} & \multirow[b]{2}{*}{ Sig. } \\
\hline & & B & Std. Error & Beta & & \\
\hline 1 & (Constant) & 9.670E-03 & .027 & & .359 & .720 \\
\hline & female & .143 & .043 & .237 & 3.331 & .001 \\
\hline & yrs grad to PDS & 1.140E-03 & .002 & .032 & .724 & .469 \\
\hline & $\begin{array}{l}\text { interact: female \& } \\
\text { years since grad }\end{array}$ & & .003 & .099 & 1.446 & .149 \\
\hline
\end{tabular}

a. Dependent Variable: non-full-time

\section{Table 12: Part-Time status, Gender, and Work Experience}

Part-Time Status vs. Gender, Experience, and Gender/Experience Interactiơn

\begin{tabular}{|c|c|c|c|c|c|c|}
\hline \multirow[b]{2}{*}{ Model } & & \multicolumn{2}{|c|}{$\begin{array}{c}\text { Unstandardized } \\
\text { Coefficients }\end{array}$} & $\begin{array}{l}\text { Standardi } \\
\text { zed } \\
\text { Coefficien } \\
\text { ts } \\
\end{array}$ & \multirow[b]{2}{*}{$\mathrm{t}$} & \multirow[b]{2}{*}{ Sig. } \\
\hline & & B & Std. Error & Beta & & \\
\hline \multirow[t]{4}{*}{1} & (Constant) & $1.143 \mathrm{E}-02$ & .023 & & .500 & .617 \\
\hline & female & .110 & .037 & 218 & 3.011 & .003 \\
\hline & yrs grad to PDS & 4.911E-04 & .001 & .016 & .367 & .714 \\
\hline & $\begin{array}{l}\text { interact: female \& } \\
\text { years since grad }\end{array}$ & 1.865E-03 & .003 & .049 & .705 & .481 \\
\hline
\end{tabular}

a. Dependent Variable: part-time

A separate set of regressions included variables for having children, in some cases breaking down the ages of children into categories: young $5 \mathrm{w}$ (youngest child living with the respondent is five years old or less), yung618w (youngest child living with the respondent is older than 5 and under 19), and young18w (youngest child living with the 
respondent is older than 18). ${ }^{55}$ In each of these regressions, parttime is the dependent variable.

Table 13 shows the results of regressions with the following explanatory variables: female, wed_now (married or remarried), anywith (any children living with), and femwith (the interactive variable generated by multiplying female and anywith). The table displays a series of regression results with the explanatory variables added one at a time, so that the final set of results shows the full model.

In these results, marital status seems to have no explanatory power at all for working part-time. Female and anywith seem at first to matter, but adding femwith in the fourth model radically reduces the statistical significance of those variables. ${ }^{56}$ This suggests that being a woman with children living at home is the biggest determinant of

55 The discussion that follows relies on several of the variables discussed in the preceding section, which discussed regressions of logged income against parenting status, children's ages, etc. Because of the time inconsistencies between the SUPP and the PDS (Jan 1998 vs. 1996), noted earlier, those variables (such as ageyoung) were re-calculated back to 1996 to maintain consistency with the income variable from the PDS. For the purposes of the analysis in this section (employment status in January 1998), though, there is no time consistency problem, because the SUPP asked about both children in January 1998. Therefore, those same child-oriented variables can be used in their original form, without the necessity of re-calculation. Having created two logically equivalent sets of variables keyed to different dates, the results here are reported using the same variable names for the children's ages (e.g. anywith = “one or more children living with the respondent in [1996 or January 1998]”) even though the regressions were run on separate datasets for the different time periods. See note 35 above.

56 In the Binomial Logit Model, the p-value for anywith is just above 0.05, but its sign is counter-intuitive. 
being part-time, but that being married has no apparent effect.

Table 13: Part-Time Status, Sex, Marriage, and Children

Coefficients $^{\mathrm{a}}$

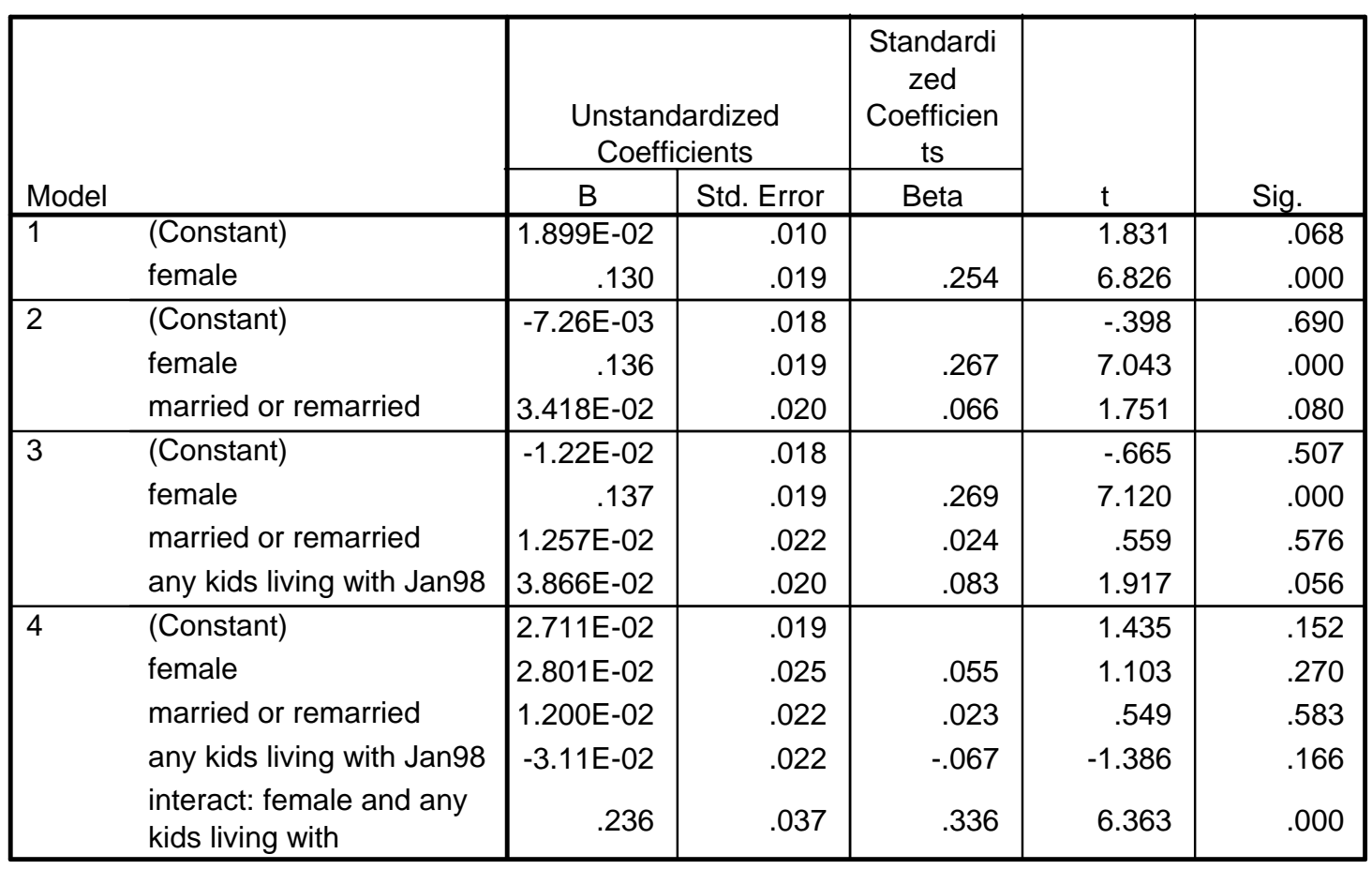

a. Dependent Variable: part-time

Because of the apparent lack of explanatory power of the wed_now variable,

Table 14 shows the results of regressions with the only the other three explanatory

variables from Table 13: female, anywith (any children living with), and femwith. After

dropping the wed_now variable, almost exactly the same patterns appear, where femwith

is the important explanatory variable, making the apparent significance of female in the

first two models disappear. 


\section{Table 14: Part-Time Status, Sex, and Children}

\begin{tabular}{|c|c|c|c|c|c|c|}
\hline \multicolumn{7}{|c|}{ Coefficients $^{a}$} \\
\hline \multirow[b]{2}{*}{ Model } & & \multicolumn{2}{|c|}{$\begin{array}{l}\text { Unstandardized } \\
\text { Coefficients }\end{array}$} & \multirow[t]{2}{*}{$\begin{array}{c}\text { Standardi } \\
\text { zed } \\
\text { Coefficien } \\
\text { ts }\end{array}$} & \multirow[b]{2}{*}{$\mathrm{t}$} & \multirow[b]{2}{*}{ Sig. } \\
\hline & & B & Std. Error & & & \\
\hline & (Constant) & $1.887 \mathrm{E}-02$ & .010 & & 1.831 & .068 \\
\hline & female & .127 & .019 & .252 & 6.782 & .000 \\
\hline \multirow[t]{3}{*}{2} & (Constant) & $-6.20 \mathrm{E}-03$ & .014 & & -.441 & .659 \\
\hline & female & .134 & .019 & .264 & 7.091 & .000 \\
\hline & any kids living with Jan98 & 4.513E-02 & .017 & .097 & 2.607 & .009 \\
\hline \multirow[t]{4}{*}{3} & (Constant) & 3.302E-02 & .015 & & 2.209 & .028 \\
\hline & female & 2.531E-02 & .025 & .050 & 1.018 & .309 \\
\hline & any kids living with Jan98 & $-2.55 \mathrm{E}-02$ & .020 & -.055 & -1.270 & .205 \\
\hline & $\begin{array}{l}\text { interact: female and any } \\
\text { kids living with }\end{array}$ & & .037 & .338 & 6.459 & .000 \\
\hline
\end{tabular}

a. Dependent Variable: part-time

Adding variables for the ages of children living with the respondent, Table 15 shows the results of regressions with the explanatory variables female, femwith, young $5 \mathrm{w}$, yung618w, and young18w. Adding the ages of the children changes nothing. The female variable is again no longer significant after femwith enters the equation, and the age-ofchildren variables are insignificant.

Changing gears somewhat, Table 16 looks at regressions with explanatory variables for the job sector in which the respondent first worked after law school. The explanatory variables are: female, femwith, busi/fin (first job in business or finance), govt (first job in government), leg/svc (first job in legal services or public interest), and other (first job in some other non-private practice sector). ${ }^{57}$

$57 \quad$ Note again that the output on the tables does not use the variable names, but instead describes the explanatory variables. 


\section{Table 15: Part-Time Status, Sex, and the Ages of Children}

\section{Coefficients $^{a}$}

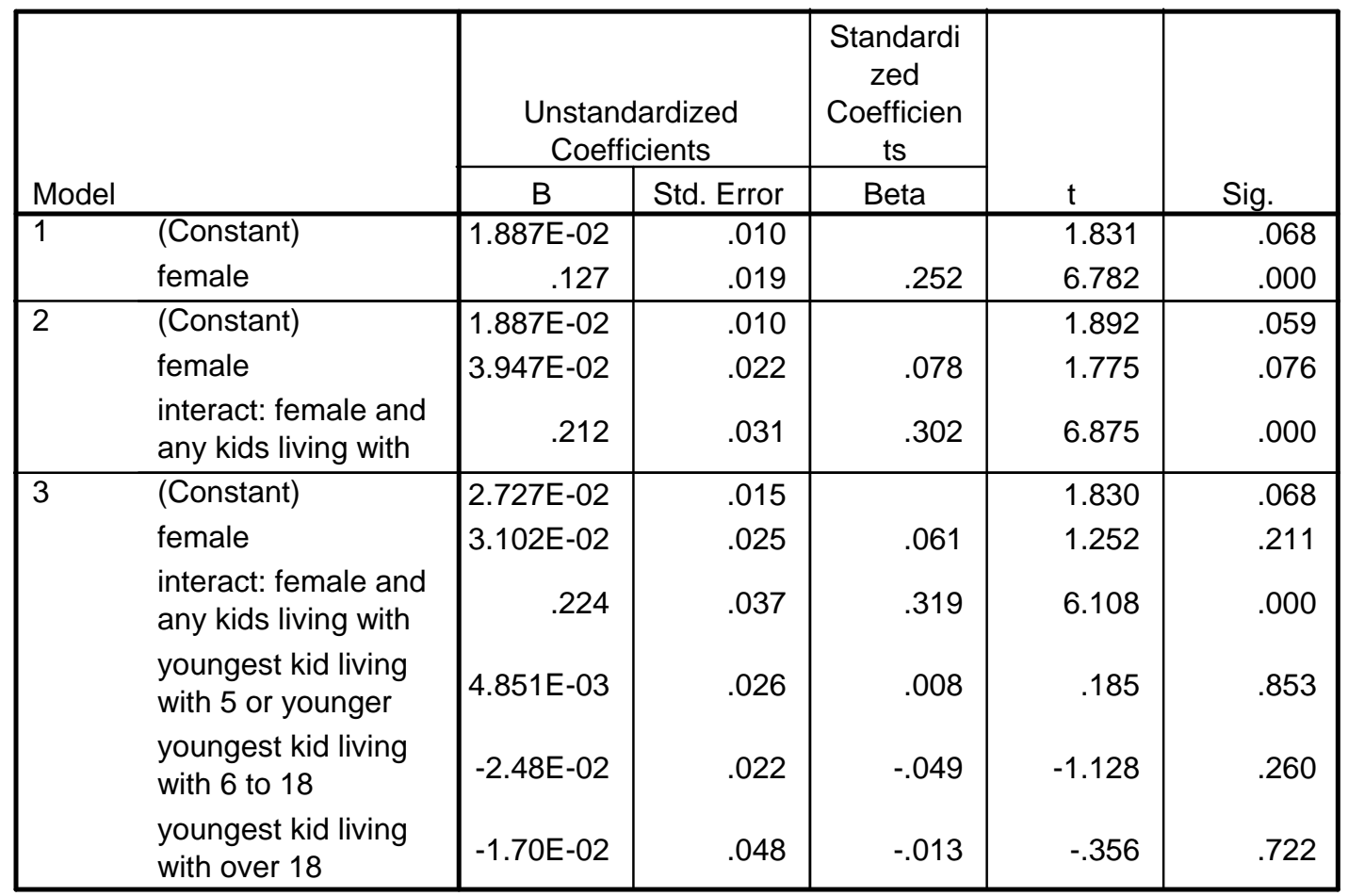

a. Dependent Variable: part-time

The hypothesis that motivated this set of regressions was that people who chose certain job sectors coming out of law school would be more or less likely to be parttimers now. These results do not support that hypothesis. The female variable becomes statistically significant in the Binomial Logit Model (not shown), which would suggest that being a woman is itself correlated with part-time status, independent of parental status, but none of the job variables are statistically significant. Again, femwith is the only statistically significant variable. 


\section{Table 16: Part-Time Status, Sex, Children, and Job Sector}

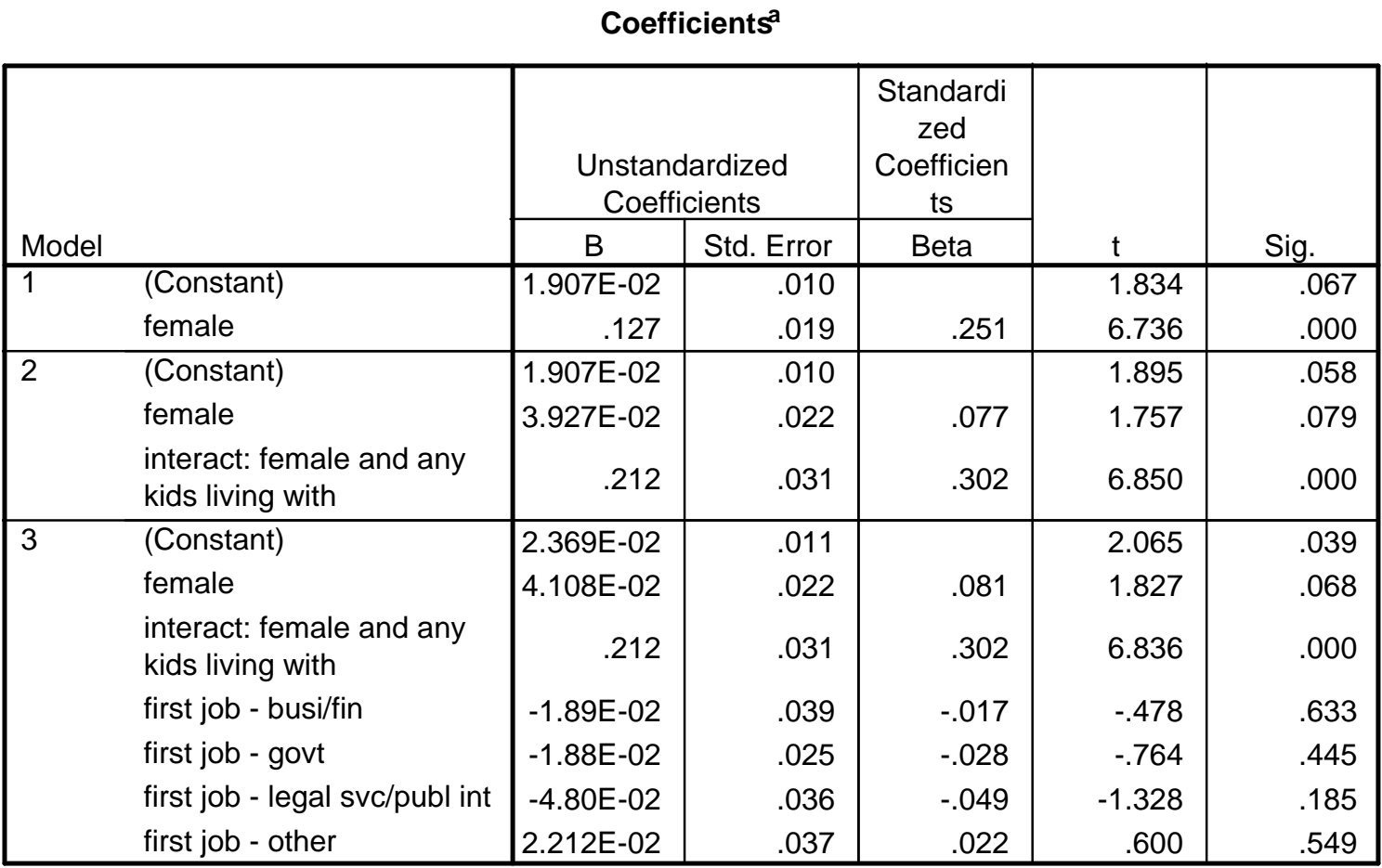

a. Dependent Variable: part-time

It is also noteworthy how consistent the point estimates were for the femwith variable, running between 0.212 and 0.238 on these four regressions. These statistically significant estimates suggest that being a woman with children makes a respondent more than $20 \%$ more likely to work part-time.

Again, however, these regressions must be taken with a grain of salt, because of the small number of respondents who reported their work status as part-time. Nevertheless, these results suggest several tentative conclusions: 1) marital status is not statistically correlated with work status, 2) being female in itself does not seem to correlate with being part-time, but 3) being both female and having children living at home is highly significant in determining work status. These results clearly comport with some common intuitions about the continuing, traditional division of labor within 
marriages - although it is perhaps surprising to see it in marriages between highly trained professionals, where both partners have invested heavily in their own earning power.

\section{Hours Worked}

As noted above, an alternative to looking at regressions with parttime or non_ft as dependent variables is to regress hours worked on similar sets of explanatory variables. Before looking at regression results, however, Table 17 provides descriptive statistics for three variables from the SUPP: weeks worked in 1996, average hours/week 1996, and total hours worked $1996 .{ }^{58}$ Not surprisingly, mean weeks worked were quite high and mean weekly hours worked were well in excess of forty hours-even though both of these averages include part-time workers and non-employed respondents. Clearly, these lawyers put in a significant number of hours at their jobs.

A large number of regressions were run on the SUPP data, regressing a variety of combinations of explanatory variables (experience, family status, employment variables, and race variables) against "hours worked in 1996" as the dependent variable. Results are available for a larger number of regressions than can usefully be presented here. Therefore, rather than discussing the models individually and displaying each in its own table, it is preferable to summarize the basic findings from the entire battery of regressions. The results for one representative regression appear below.

58 Again, the variables discussed here, as in the regressions in the section discussing income, were adjusted to reflect parenting status in 1996. See note 34 above. 


\section{Table 17: Weeks and Hours Worked, 1996}

\section{Descriptive Statistics}

\begin{tabular}{|l|r|r|r|r|r|}
\hline & \multicolumn{1}{|c|}{$\mathrm{N}$} & Minimum & Maximum & \multicolumn{1}{c|}{ Mean } & Std. Deviation \\
\hline weeks worked 1996 & 683 & 0 & 52 & 46.42 & 10.05 \\
ave hours/wk & 677 & 0 & 85 & 48.43 & 12.75 \\
worked 1996 & 675 & 0 & 4420 & 2317.43 & 721.38 \\
hours worked 1996 & 675 & & & & \\
Valid N (listwise) & & & & \\
\hline
\end{tabular}

In short, the results of these regressions indicate that none of the following are significantly correlated with hours worked: work experience (years to PDS), marital status, sex/gender, position in an organization (partner, etc.), or ages of children. Being a woman with children living at home (femwith, which as above is the interactive variable defined as female times anywith), though, is again highly significant across all of the regressions. The point estimates indicate that being a woman with children at home reduces work hours by 650-700 hours per year, from the mean hours worked for the sample of slightly over 2300 .

Table 18 displays the results of one of the regressions, showing that femwith (listed, as in Tables 13-16, as “interact: female and any kids living with”) is highly statistically significant when it is first entered as the only explanatory variable, and it maintains its significance even as variables for race and first-job sector are added. Some of the variables for the sector in which the respondent first worked (business/finance and “other”) provide some explanatory power in this regression as well.

It is also interesting that in these regressions-though not in some of the regressions not displayed here-race was a statistically significant variable. This was true both in regressions with race as a single variable (minority) and in regressions, as in Table 18, that broke race down into the four nonwhite categories. (The effect for Asians 
was not statistically significant, even in the regressions where the other three categories were significant. Again, though, the extremely small number of Asian respondents makes that result unsurprising.) These results show that being a member of any minority correlated with longer work hours.

\section{Table 18: Hours Worked, Children, Race, and First-Job Sector}

\section{Coefficients $^{\mathrm{a}}$}

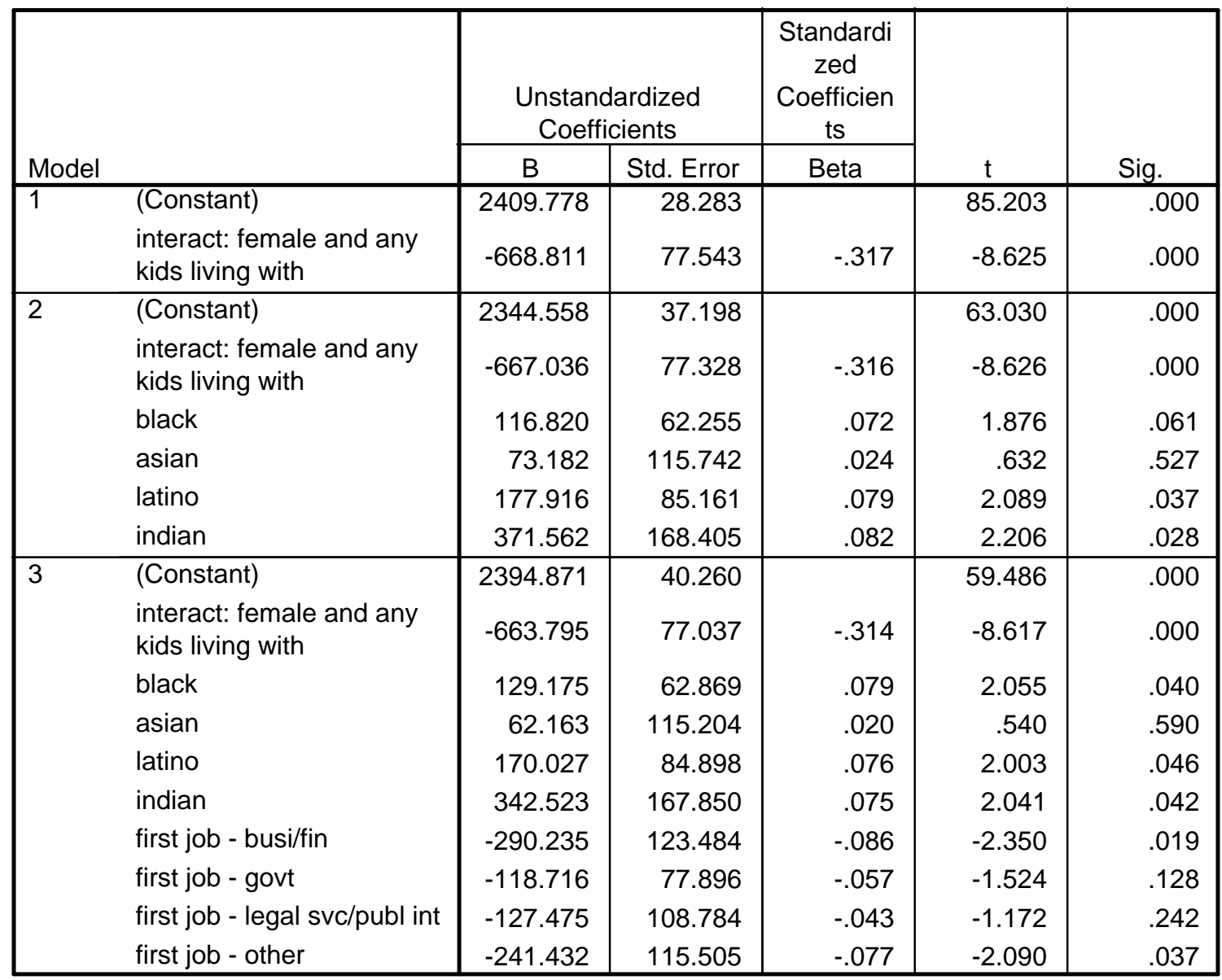

a. Dependent Variable: hours worked 1996

These results, therefore, comport with the results reported in the previous section, regarding respondents who work part-time. The variable femwith seems to be the 
only consistently reliable variable in predicting hours worked, increasing the strength of the inference that, even in the mid- to late 1990's, women with children at home reduced their paid work hours to care for their children, while men did not.

\section{Conclusion}

The data in the Professional Development Survey (PDS) and the Supplementary Questionnaire (SUPP) provide a fascinating insight into the lives of the graduates of the University of Michigan Law School. While there are differences in the response pools for the two surveys, and while there is some evidence that those differences might bias the results of statistical regression analyses, comparison of regressions on the SUPP data with identical regressions run on the PDS data indicate a high level of congruence. Statistical inferences from analysis of the SUPP data, therefore, offer potentially valuable insights into the careers of University of Michigan-trained lawyers.

The analyses summarized here focus on three outcome variables: income, work status (full-time, part-time, and not employed), and hours worked per year. For the analyses of differences in income, the results indicate that fathers received a bonus and mothers paid a penalty, compared to childless men and women. (There is also some suggestion of a penalty even for childless women, although the statistical robustness of that result is somewhat weak.) These results contrast with those of other studies that suggest a bonus for fathers but no penalty for mothers.

The data on work status showed that very small numbers of Michigan graduates identified themselves as working part-time or not being employed. Even so, the data indicate that non-full-time workers are frequently mothers who have changed their work 
status in order to provide care to their children. Being a mother with children living at home is significantly correlated with a higher probability of working part-time.

Similarly, the results for regressions on annual hours worked (independent of full-time work status) indicate that mothers reduce their hours on the job by, on average, 650-700 hours per year, from a group-wide average of 2300 hours worked per year. In other words, both the "work status" results and the "hours worked” results suggest that, even for this highly trained group of professionals, mothers divert hours from work life to home life to accommodate the presence of children in the home in ways that fathers do not.

Clearly, detailed study of all of these questions should continue. Fortunately, researchers at the University of Michigan are in the process or collecting survey data from larger numbers of graduates for more years, which will facilitate future efforts to test and perhaps extend the results summarized here. 